San Jose State University

SJSU ScholarWorks

Master's Theses

Master's Theses and Graduate Research

1995

\title{
A study of the relationship between the Glasgow Coma Scale and the Functional Independence Measure of adult individuals with brain injuries
}

Jacalyn Joan Wiedenhoeft

San Jose State University

Follow this and additional works at: https://scholarworks.sjsu.edu/etd_theses

\section{Recommended Citation}

Wiedenhoeft, Jacalyn Joan, "A study of the relationship between the Glasgow Coma Scale and the Functional Independence Measure of adult individuals with brain injuries" (1995). Master's Theses. 1040. DOI: https://doi.org/10.31979/etd.fh93-adzc

https://scholarworks.sjsu.edu/etd_theses/1040

This Thesis is brought to you for free and open access by the Master's Theses and Graduate Research at SJSU ScholarWorks. It has been accepted for inclusion in Master's Theses by an authorized administrator of SJSU ScholarWorks. For more information, please contact scholarworks@sjsu.edu. 


\section{INFORMATION TO USERS}

This manuscript has been reproduced from the microfilm master. UMI films the text directly from the original or copy submitted. Thus, some thesis and dissertation copies are in typewriter face, while others may be from any type of computer printer.

The quality of this reproduction is dependent upon the quality of the copy submitted. Broken or indistinct print, colored or poor quality illustrations and photographs, print bleedthrough, substandard margins, and improper alignment can adversely affect reproduction.

In the unlikely. event that the author did not send UMI a complete manuscript and there are missing pages, these will be noted. Also, if unauthorized copyright material had to be removed, a note will indicate the deletion.

Oversize materials (e.g., maps, drawings, charts) are reproduced by sectioning the original, beginning at the upper left-hand corner and contiming from left to right in equal sections with small overlaps. Each original is also photographed in one exposure and is included in reduced form at the back of the book.

Photographs included in the original manuscript have been reproduced xerographically in this copy. Higher quality $6^{n} \times 9^{n}$ black and white photographic prints are available for any photographs or illustrations appearing in this copy for an additional charge. Contact UMI directly to order.

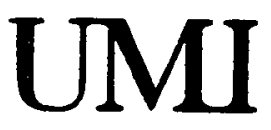

A Bell \& Howell information Company 300 North Zeeb Road. Ann Arbor. MI 48106-1346 USA 313:761-4700 800:521-0600 



\title{
A 8TODY OF THE RELATIONSHIP BETHEEN THE GLAGGON COMA BCALE \\ AND THE FUNCTIONAL INDEPENDENCE MEABURE OF ADULT INDIVIDUALS WITH BRAIN INJURIES
}

\author{
A Thesis \\ Presented to \\ The Faculty of the Deptartment of Occupational Therapy \\ San Jose State University
}

\author{
In Partial Fulfillment \\ of the Requirements for the Degree \\ Master of Science
}

by

Jacalyn Joan wiedenhoeft, OTR

May 1995 
OMI Number: 1374631

Copyright 1995 by

wiedenhoeft, Jacalyn Joan

All rights reserved.

OMI Microform 1374631

Copyright 1995, by UMI Company. All rights reserved.

This microform edition is protected against unauthorized copying under Title 17, United States Code.

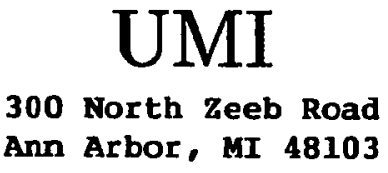


- 1995

Jacalyn Joan Wiedenhoeft

ALL RIGHTS RESERVED 
APPROVED FOR THE DEPARTMENT OF OCCUPATIONAL THERAPY

$$
\frac{\text { Houdon A. Hentorar }}{\text { Gordon U. Burton, Ph.D., OTR }}
$$

Heidi Mettuch Pendlitr

Heidi PendletEn, MA, OTR, Ph.D. Card.

Brenda (avion dire

Brenda collins, OTR

APPROVAL FOR THE UNIVERSITY

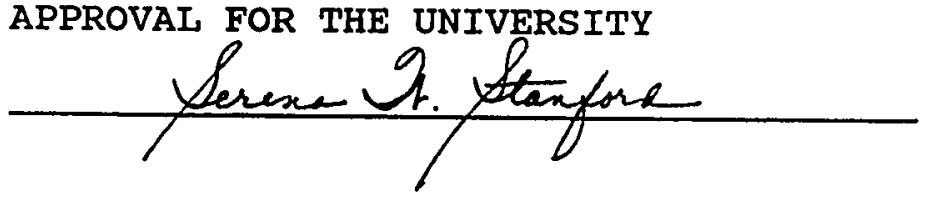




\section{ABSTRACT}

A BTUDY OF THE RELATIONBHIP BETWEEN THE GLABGON COMA SCALE AND THE FUNCTIONAL INDEPENDENCE MEAgURE OF ADULT INDIVIDUALS WITH BRAIN INJURIES

by Jacalyn J. Wiedenhoeft, OTR

This study examined the relationship between the level of consciousness, as measured by the Glasgow Coma scale (GCS), and the ability to perform functional activities, as measured by the Functional Independence Measure (FIM), of 38 adult individuals with brain injury. The design of the study was non-experimental using ex post facto data to establish the relationship between the GCS scores, established within 24 hours of an accident and the discharge FIM scores, established during the brian injured patients' rehabilitation.

This study inquired as to whether or not the Gcs could be a valid predictor for establishing realistic functional outcomes for people with brain injuries as represented by FIM scores. In this study no significant ( $\underline{0} \leq .05)$ relationship was established between the GCS and the FIM; therefore, the scores on the Glasgow Coma Scale were found not to be a valid predictor of scores on the Functional Independence Measures at Discharge. 
Acknowledgement

There are so many individuals that contributed to the completion of this thesis. The list is endless. Thanks to all of you. A special thanks for their support, encouragement and for putting up with my complaining and confusion goes to my family, friends, and co-workers.

I could not have achieved this without the support of my parents. Dad, you finally received your cadillac.

A major contributor to my life who can not be forgotten, is my dearest friend Dan starr. Dan encouraged me to follow my dreams even when I wanted to quit, and supported me no matter what, over the years.

The timeliness and encouragement from my readers Brenda Collins, OTR, Andres Fernandez, MSW, and Dr. Heidi Pendleton was greatly appreciated. Thanks so much to Dr. Wayne clark, Dr. Vicki Krems, and Dr. Eric Krems for their help and guidance with my statistics. Thanks to Mark stevenson for his patience and time with developing my graphs.

Last but not least, I extend my gratitude and thanks, for his guidance and patience through this process, to my thesis advisor Dr. Gordon U. Burton. 


\section{Table of Contents}

List of Tables $\ldots \ldots \ldots \ldots \ldots \ldots \ldots \ldots \ldots \ldots \ldots \ldots \ldots \ldots$ vii

List of Figure $\quad \ldots \ldots \ldots \ldots \ldots \ldots \ldots \ldots \ldots \ldots \ldots \ldots \ldots \ldots$ viii

\section{Chapters}

1. INTRODUCTION $\ldots \ldots \ldots \ldots \ldots \ldots \ldots \ldots \ldots \ldots \ldots \ldots \ldots \ldots \ldots$

Purpose $\ldots \ldots \ldots \ldots \ldots \ldots \ldots \ldots \ldots \ldots \ldots \ldots \ldots \ldots \ldots \ldots \ldots$

Statement of the Problem ................... 2

objectives ........................... 4

questions $\ldots \ldots \ldots \ldots \ldots \ldots \ldots \ldots \ldots \ldots \ldots \ldots \ldots \ldots \ldots$

Definitions ........................... 6

Assumptions $\ldots \ldots \ldots \ldots \ldots \ldots \ldots \ldots \ldots \ldots \ldots \ldots$

Limitations $\ldots \ldots \ldots \ldots \ldots \ldots \ldots \ldots \ldots \ldots \ldots \ldots \ldots$

Significance of the study $\ldots \ldots \ldots \ldots \ldots \ldots \ldots \ldots \ldots \ldots$

2. REVIEW OF THE LITERATURE

Introduction ......................... 10

GCS Reliability and validity ............... 11

GCS studies ............................ 12

FIM Reliability and Validity .............. 16

FIM studies ......................... 16

Conceptual Frame of Reference ............... 17 
Chapters

3. DESIGN AND METHODOLOGY

Research Procedures ...................... 20

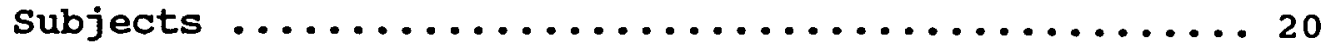

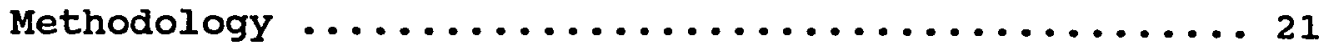

4. ANALYSIS OF DATA

Introduction $\ldots \ldots \ldots \ldots \ldots \ldots \ldots \ldots \ldots \ldots \ldots \ldots \ldots \ldots$

subjects $\ldots \ldots \ldots \ldots \ldots \ldots \ldots \ldots \ldots \ldots \ldots \ldots \ldots \ldots \ldots \ldots \ldots . \ldots \ldots$

Research Questions .................... 27

5. RESULTS, PROFESSIONAL IMPLICATIONS RECOMMENDATIONS AND BUMMARY

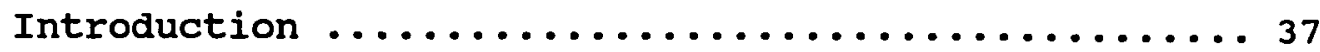

Research Questions ....................... 39

Implications for the Profession ...............41

Further Implication for Research ............. 42

References $\ldots \ldots \ldots \ldots \ldots \ldots \ldots \ldots \ldots \ldots \ldots \ldots \ldots \ldots \ldots$

\section{APPENDICES}

A. Letter of permission for utilization of the Glasgow Coma scale .................. 51

B. GLAgGON COMA SCALE ................... 53 
Appendices continued

c. Letter of permission for utilization of the

Functional Independence Measure ........... 58

D. Functional Independence Measure ...........60 60

E. Human subjects Approval ................. 81

F. Facility Approval ................... 83

viii 
List of Tables

Table

1. Means and standard Deviations of the GCS

and the FIM scores....................... 36

ix 
List of Figures

Figure

1. OCCUPATIONAL PERFORMANCE FRAME OF REFERENCE ....... 19

2. Male and Female Ethnic Representation ........... 24

3. Age Representation of Individuals

with Brain Injuries ...................... 25

4. Length of stay in Rehabilitation ............. 26

5. Glasgow Coma scale Representation ............. 28

6. Discharge FIM scores for self-Feeding ........... 29

7. Discharge FIM scores for Grooming ............ 30

8. Discharge FIM scores for opper Body Dressing ...... 31

9. Discharge FIM scores for Lower Body Dressing ...... 32

10. Discharge FIM scores for Commode Transfers ........ 33

11. Discharge FIM scores for Transfers to

Tub or shower $\ldots \ldots \ldots \ldots \ldots \ldots \ldots \ldots \ldots \ldots \ldots \ldots \ldots \ldots \ldots$ 
CHAPTER 1

INTRODUCTION

This study was conducted to determine if a relationship existed between the performance scores of the Glasgow Coma Scale (GCS), established within 24 hours of an accident, and the Functional Independence Measure (FIM) of daily living skills upon discharge from rehabilitation, in adults with brain injuries. The Glasgow Coma Scale was designed to determine the level of consciousness of individuals with brain injuries by assessing verbal, motor, and eye responses. The FIM was designed to measure the severity of a patient's disability and the outcomes of rehabilitation regardless of the underlying pathology.

If a relationship existed between the GCS and the FIM, these measures could allow the therapist to consider both cognitive function (GCS) as well as physical function (FIM) when establishing realistic outcomes for individuals with head injuries.

\section{Purpose of Study}

The purpose of this study was to determine whether a relationship existed between performance scores on the Glasgow Coma Scale (GCS), established within 24 hours of an 
accident resulting in brain injury, and the Functional Independence Measures (FIM) of daily living skills in brain injured adults upon discharge from rehabilitation.

\section{statement of the Problem}

It is very difficult to make predictions regarding the recovery of adults with brain injuries. "Despite the wellrecognized importance of early prognosis after severe head injury, we still do not have reliable guidelines upon which the outcome can be confidently predicted" (Overgaard, Christensen, Hvid-Hasen, Haase, Land, Hein, Pedersen, \& Tweed, 1973, p. 7830). "When the brain is the organ affected, the persisting disability usually comprises both mental and physical handicaps which can seriously impair the quality of life" (Jennett \& Bond, 1975, p. 480). There are many variables that can contribute to predicting outcomes for individuals with brain injuries. One of the most important variables is the depth of coma or the level of consciousness determined by the Glasgow Coma Scale (GCS). Very limited research has been conducted on relationships between adults with brain injuries, ability to perform functional activities and their level of consciousness. Since the GCS measures the severity of injury, it could therefore be a valid predictor for establishing realistic goals if there was a positive relationship between the GCS 
and the FIM. Presently the GCS is being used to indicate levels of response of a brain injured patient within a 24 hour period following an injury. The FIM indicates the functional status of patients during their rehabilitation stay at admission, interim, and discharge.

According to Fleming, Thy, and Maas (1994), "Research to improve the accuracy of prediction of outcome has been valuable for several reasons: (1) to improve the quality of decision making about allocation of limited resources; to allow the family to adjust its expectations and plan for the future; (3) to provide a means for realistic goal setting and consequent evaluation of program effectiveness; and (4) to provide a possible basis for determining settlement payments" (p. 156).

clinicians are routinely setting goals for outcomes using their clinical judgement and estimation. "The need for adequate measurements of disability is apparent both in patient care and clinical research: for determining compensation, predicting outcomes, planning placement, establishing care requirements, and indicating change in functional status" (Heinemann, Linacre, Wright, Hamilton, \& Granger, 1993, p. 566).

Knowing that many variables contribute to the prediction of outcomes, it is imperative that clinicians consider such variables in setting treatment goals. of 
these variables, the GCS score is important in setting treatment goals, which maybe reflected in a FIM score. An ex post facto correlational study was necessary to help determine if GCS scores and FIM scores could enable therapists to predict realistic FIM goals.

A significant correlation between these two instruments would indicate that the GCS score could be used as a valid predictor of FIM scores. This could theoretically increase the accuracy of the therapists' ability to predict realistic outcomes. Therapists would then be able to contribute to the discharge planning process earlier and establish more cost effective care in the patient's overall treatment plan.

\section{Objective}

The overall objective of this study was to explore the relationship between the Glasgow coma scale score, established within 24 hours of an accident, and the Functional Independence Measures in the areas of selffeeding skills, grooming, dressing, transfers to the commode, and into the tub or shower. The stated FIM scores reflect the adult brain injured patient's level of function at the time of discharge from Leon $s$. Peters Rehabilitation Center, an acute inpatient rehabilitation center. 
Specific Objectives

The objectives of this research were to:

1. Determine if a relationship exists between performance scores on the Glasgow Coma Scale (GCS) and the Function Independence Measure (FIM) in adults with brain injury.

2. Determine the degree of correlation, if any.

Questions

The questions addressed by this research were:

1. In the sample studied, what were the Glasgow Coma Scale scores for patients with brain injuries?

2. In the sample studied, what were the Functional Independence Measure discharge scores in the areas of self-feeding, grooming, dressing, and bathroom transfers?

3. What was the relationship between the Glasgow Coma Scale level, established within 24 hours of an accident, and the Functional Independence Measure in specific daily living activities?

4. Could the Glasgow Coma Scale score predict the discharge scores of the Functional Independence Measure? 
Definitions

The operational definitions of the FIM areas utilized throughout this study were as follows:

Self-feeding: Includes use of suitable utensils to bring food to the mouth, chewing and swallowing, once the meal is appropriately prepared.

Grooming: Includes oral care, hair grooming, washing hands and face, and either shaving or applying make-up. If there is no preference for shaving or applying make-up, then disregard.

Dressing: Upper body: Includes dressing above the waist as well as donning and removing prothesis or orthosis when applicable.

Dressing: Lower body: Includes dressing from the waist down as well as donning or removing prothesis or orthosis when applicable.

Transfers: Toilet: Includes getting on and off a toilet. Tub or Shower: Includes getting into and out of a tub or shower stall.

Activities of Daily Living (ADL's): "the performance of the activities necessary during the course of an ordinary day for independence" (Reed, 1984, p. 227).

All the above mentioned areas are further qualified by levels of assistance needed as seen in Appendix D. The operational definitions of the GCS utilized throughout 
this study are defined in Appendix B.

\section{Assumptions}

During the study, the following assumptions were made.

1. The GCS score was determined within 24 hours of the accident, as reported.

2. The patients had an adequate length of stay at the rehabilitation center to facilitate change in functional status.

\section{Limitations}

Several limitations were identified in this study. The research sample was small and was obtained from only one rehabilitation facility. Due to the small sample size generalization of data was not possible. The sample was not random; it was limited to adult brain injured patients who had pre-established GCS scores at the site of this study. Inter-rater reliability was not examined in this study. Another limitation was the patient's length of stay. This can be affected by funding or by complications, such as lack of a caregiver or a change in medical status. The length of stay may greatly affect the FIM discharge scores. Shorter length of stays may produce a lower FIM discharge score.

The rehabilitation center serves a very culturally 
diverse population. As a result of cultural diversity, many different languages were present. Although interpreters were utilized to overcome language barriers, cultural barriers still may have existed, which may have affected outcome measures. As a result of the cultural barriers, the functional independence measures may be lower than in other geographical areas.

Other studies have indicated that the utilization of the total GCS score could be effected by a lack of verbal response or communication score due to intubation, induced paralysis, or drug intoxication. The GCs motor score has been proven to be a better predictor of recovery (spettell, et al., 1991). The total GCS score reliability was uncontrolled in this study, because it was already established in the medical chart. The sample size was limited to only those patients with established GCS scores.

\section{Significance of the study}

This study was undertaken to examine if a significant relationship between the Functional Independence Measure (FIM) and the Glasgow Coma Scale (GCS) could have been established. If a relationship existed, these measures may have provided a predictor for the therapist to establish goals for individuals with brain injuries. These measures could have allowed the therapist to consider both cognitive 
function (GCS), as well as physical function (FIM) when establishing goals. This study determined that the GCS does not correlate to function. Further indicating that the GCS score should not be relied upon as a predictor of FIM scores at discharge. 


\section{CHAPTER 2}

REVIEW OF THE IITERATURE

Despite modern advances in technology and safety measures, closed head injuries still occur. "Closed head injuries account for approximately $20 \%$ to $30 \%$ of all trauma admissions" (Taheri, Karamanoukian, Gibbons, Waldman, Doerr, \& Hoover, 1993, p. 289). Spettell, Ellis, Ross, Sandel, o'Malley, stein, and Spivack (1991) stated that approximately $65 \%$ of patients who sustain brain injuries survive. However, in many cases the survivor's recovery is marked by prolonged and often permanent deficits in the areas of cognition, behavioral, psychosocial and physical disabilities. One third to one half of survivors of severe brain injury are at least moderately disabled. Other survivors are severely disabled or remain in a vegetative state (p. 320).

Based on these statistics, it is important to predict outcomes for survivors of severe brain injury to ensure the best course of treatment planning as well as decision making regarding rehabilitation and long-term care. 
There are many variables that affect the ability to predict the outcomes of severe brain injury survivors. These include duration of coma, age, pupillary responses, the presence of mass lesions requiring neurosurgery, elevated intracranial pressure, evoked potentials and various blood and cerebrospinal fluid factors.

"One of the major variables used to predict outcome is severity of brain injury. Many studies have used the initial evaluation of the patients to predict outcome from brain injuries" (Spettell et al., 1991, p. 320). Included in the initial evaluation, is a rating scale of the depth of coma at the time of admission or during the first 24 hours after trauma. The scale most often used is the Glasgow coma Scale (GCS).

The GCS was developed in 1974 for patients with acute head injury to determine the level of consciousness. It determines the level of consciousness by assessing the following three areas: verbal, motor and eye response. The GCS is rated on a scale of 3 through 15 . A level 3 indicates the lowest response and a level 15 indicates the highest response. A GCS score of seven or less indicates comatose, whereas a score of greater than seven indicates not comatose (see Appendix B) (Choi, Narayan, Anderson, \& Ward, 1988; Rimel \& Tyson, 1979).

The reliability of the Glasgow Coma scale is $\underline{r}=.90$ 
(Giacino, Keymarsky, Deluca, \& Cicerone, 1991). The Lyle, Pierce, Freeman, Bartrop, Dorsch, Fearnside, Rushworth, and Grant (1986) study indicated that the "widespread use of the GCS has led to greater reliability and uniformity in the early assessment of head-injured patients" (p. 18); however, the accuracy of the scale to indicate the potential for clinical improvements has been shown to diminish over a prolonged period of time. This suggests that the GCS should only be used to predict recovery within the first 24 hours. There have been many studies which utilize the Glasgow Coma score of 7 or less as a criterion for participation. Few studies though use the GCS score alone as a tool for correlation or precise measure.

A correlational study between 21 variables and prediction of outcomes determined that many variables alone show a strong correlation with outcome (Choi, Narayan, Anderson, \& Ward, 1988). However, a combination of "age, motor response and pupillary response yielded a more compact yet highly predictive model" (p. 382) for predicting outcomes for a patient with a brain injury into one of four categories (good recovery, moderate disability, severe disability, or vegetative/dead).

Heinemann, Linacre, Wright, Hamilton and Granger (1994) conducted a study investigating "the importance of several predictors of two kinds of rehabilitation outcome: 
independence in function at discharge and length of stay" (p. 133). The study utilized the FIM to indicate the functional status at admission and discharge. Heinemann et al. (1994) discovered that age, promptness of admission to rehabilitation, and frequency of rehabilitation interruptions were often significant predictors among neurological conditions. The areas most affected by these predictors were discharge cognitive function and length of stay for individuals with brain injuries.

Functional status upon admission was "consistently related to discharge function and length of stay. The strength of these associations varies across impairment groups" (Heinemann et al., 1994, p. 141). Heinemann et al. (1994) also stated that the "relative unimportance of cognition in predicting length of stay suggests that the kinds of goals that justify rehabilitation stays are more strongly determined by physical function than by cognitive function" (p. 142).

Much of the literature (including the works of Waxman, Sundine, and Young (1991), spettell et al. (1991) and Choi et al. (1988)) has indicated that the sum of the Gcs is misleading secondary to the inaccuracy of obtaining verbal response score. The verbal response may not be obtained due to intubation, induced paralysis, or intoxication. The motor score alone gives a better description than the sum of 
the GCS, indicating that the scores of the three areas assessed should be documented separately and not in a total GCS score. If the sum of the score is utilized it assumes an equal weighting for the three responses. More importantly, the information conveyed by the coma score is less than that contained in the three responses separately. This is because the same score may be made up in different ways (Teasdale, Jennett, Murray, \& Murray, 1983, p. 678).

A key study which relates to this research is one conducted by Gothoh, Tamura, Oka, Tsujita, Sano, Yasui, Suzuki, Hadeishi, Nihei, and Manaka (1993), which correlated the GCS with the Glasgow Outcome Scale (GOS). The GOS has five categories, which are good recovery, moderate disability, severe disability, persistent vegetative state and death. "These categories have sometimes been condensed into two, representing either favorable or poor outcomes" (Spettell et al., 1991, p. 321). The results of the Gothoh et al. (1993) study indicated that the higher the GCS the better the outcomes.

Over the last 15 years studies have used the Glasgow outcome Scale (GOS) to predict overall outcomes for brain injured individuals (Spettell et al., 1991). In the rehabilitation arena the most widely used mechanism for rating outcome is the Functional Independence Measure (FIM). 
The FIM was developed at the state University of New York Buffalo, by a national task force, which was sponsored by the American Congress of Rehabilitation Medicine and the American Academy of Physical Medicine and Rehabilitation. It became a part of the Uniform Data system for Medical Rehabilitation (UDSMR). The FIM was designed to measure the severity of a patient's disability and the outcomes of rehabilitation regardless of the underlying pathology and to be reliable regardless of the clinical background of the user (Byrnes \& Powers, 1989; Heinneman et al., 1993). The FIM is comprised of eighteen items within six subcategories, which include self-care (feeding, grooming, bathing, dressing: upper body, lower body, toileting), Sphincter Control (bowel and bladder management), Mobility (transfers to bed, chair or wheelchair, to toilet, and to tub or shower), Locomotion (walking or wheelchair propulsion, stair climbing), Communication (comprehension and expression), Social Cognition (social interaction, problem solving and memory). These areas are assessed on a seven-level scale. The scale is based on the level of assistance needed (see Appendix D).

The Functional Independence Measure "content validation is limited to face validity" (Granger, Hamilton, Kieth, Zielezny, \& Sherwin, 1986, p. 68). "The interrater reliability of the FIM has been established as $\underline{r}=0.95^{\prime \prime}$ 
(Byrnes \& Powers, 1989, p. 62). "Determination of precision of the instrument (ie how small a change is detectable from admission to discharge) revealed significant differences in FIM scores (10.7 $\pm 0.9 \mathrm{SE}$ FIM units). This finding suggests that the FIM has adequate precision" (Granger, Cotter, Hamilton, \& Fiedler, 1990, p. 871).

There have been many studies conducted by Granger, Hamilton, Cotter, Fiedler and Kieth on the development of the FIM scale and how it relates to different diagnoses. These studies were not pertainient to this study.

The FIM is a unique assessment because it not only assesses specific functional skills and mobility, but it also recognizes the importance of cognition in performing daily living skills. There are limitations of the FIM scale in both of these areas. As indicated in a study done by Davidoff, Roth, Haughton, and Ardner (1990), the FIM is limited in its ability to accurately assess cognitive deficits because it is done by observation, which leads to false negatives. It also negates minor deficits that neuropsychological batteries could detect. An optimal assessment of cognition can be obtained by utilizing the FIM in conjunction with a neuropsychological evaluation.

Another limitation of the FIM was addressed in studies by Granger et al. (1990, 1993), which compared a number of functional assessments to determine the amount of assistance 
needed by patients with Multiple Sclerosis (MS) or Cerebral Vascular Accidents (CVA) in units of time and by their quality of life. The findings of these studies indicated that the FIM was a strong tool for measuring the amount of assistance needed by MS and CVA patients in the home (1990, 1993). The limitation was that the FIM did not account for the visual deficits of patients, which may greatly impair their FIM scores. The FIM is strengthened by adding a visual assessment when limitations of vision are present (Granger et al., 1990).

There was no indication from the literature review that the level of consciousness has been compared to the FIM scale or other functional scales. Therefore, this study will set a precedent for other studies correlating levels of consciousness to functional measures.

\section{Conceptual Frame of Reference}

This study was based on the Occupational Performance frame of reference as presented by Lorraine Pedretti (1990). Occupational performance is the individual's ability to accomplish the tasks required by his or her role and related to his or her developmental stage. Roles include those of a "preschooler," student, homemaker, employee, and retired worker. Occupational performance skills includes self-care, work, and 
play/leisure time performance.... Self-care includes feeding, grooming, mobility, and object manipulation. Work activities include home and family management, employment, and education. Play and leisure include the play activities of childhood and the games, sports, hobbies and social activities of adult life (Pedretti \& Pasquinelli, 1990, p. 1). The performance components are the foundation for occupational performance skills. "The performance components include (1) sensory-integration functioning (2) motor functioning (3) social functioning (4) psychological functioning and (5) cognitive functioning" (Pedretti \& Pasquinelli, 1990, p. 1) - Performance components, as well as developmental stages and "life space, refers to the individual's cultural background and both human and nonhuman environment" (Pedretti \& Pasquinelli, 1990, p. 2), affect an individual's ability to perform occupational performance skills.

since this study examined the relationship between functional self-care skills as measured by the FIM, and cognitive functioning as measured by the GCS, it identified that the performance component of cognition affects the performance skill of self-care, as indicated in Figure 1. 


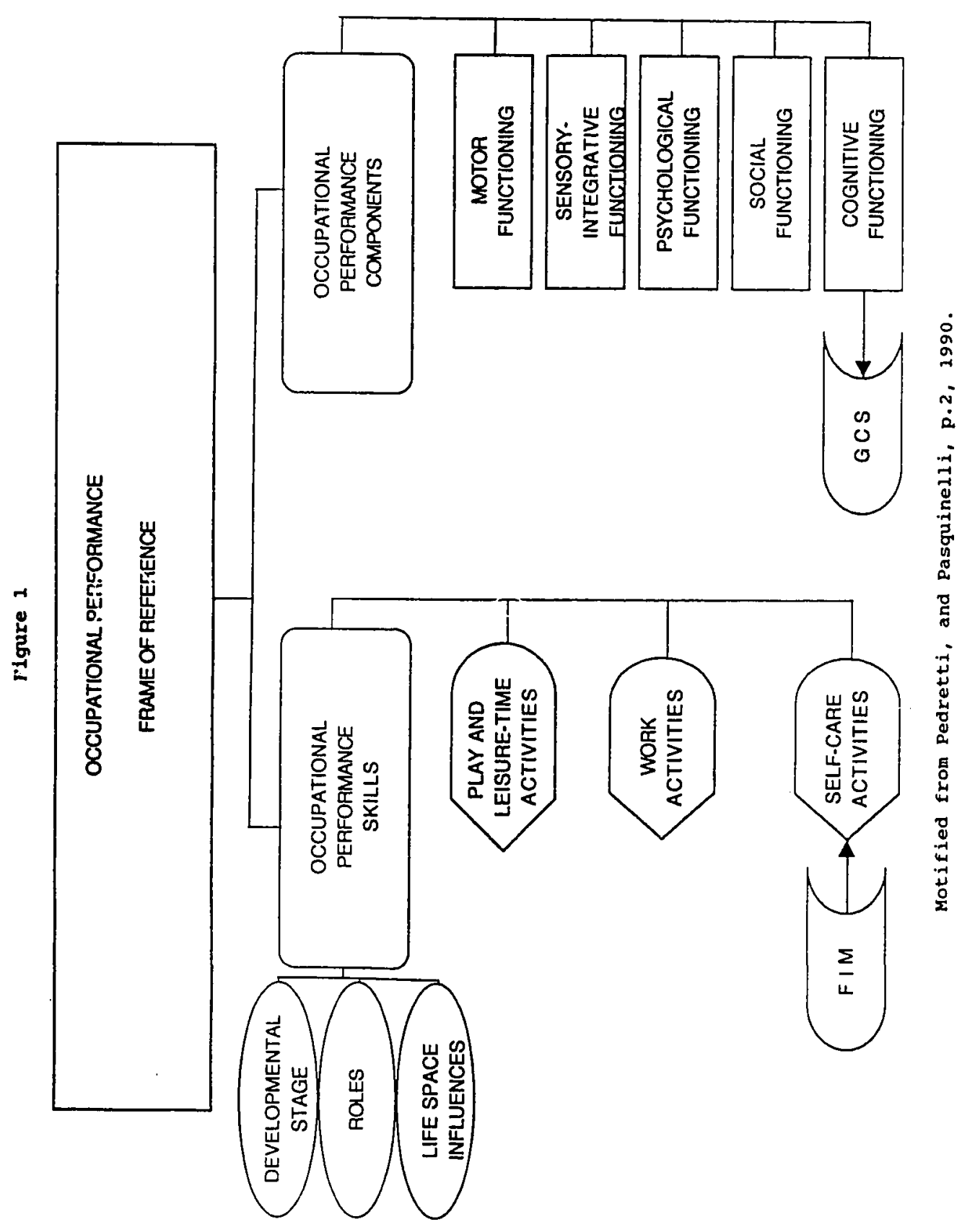




\section{CHAPTER 3}

\section{DESIGN AND METHODOLOGY}

\section{Research Procedures}

The overall objective of this study was to explore the relationship between performance scores on the Glasgow coma Scale (GCS), established within 24 hours of an accident, and the Functional Independence Measures (FIM) in the areas of self-feeding skills, grooming, dressing, and transfers to the commode and into the tub or shower upon discharge from rehabilitation. What were the FIM and the GCS scores for individuals with brain injuries? The stated FIM scores are believed to reflect the level of function of adult's with brain injuries, at the time of discharge from rehabilitation. The FIM scores were obtained from the patient's occupational therapy chart and the GCS scores for patients with brain injuries were obtained from medical records. A number was assigned to each patient's data in place of patient's name to ensure confidentiality.

\section{subjects}

The subjects for this study were selected from the Leon S. Peters Rehabilitation Center at Fresno Community Hospital and Medical Center, located in Fresno, California. The subjects were individuals who received therapy after 
acquiring a brain injury. The subjects consisted of males and females from 17 to 80 years of age. The subjects were administered the Glasgow Coma Scale within 24 hours of their accident, and had received FIM scores after participation in a rehabilitation program. The sample consisted of 38 adult individuals with brain injuries.

\section{Methodology}

The design of the study was non-experimental, ex post facto, data was examined, utilizing Glasgow Coma scale (GCS) scores established within 24 hours of an accident and discharge Functional Independence Measure (FIM) scores established during the brian injured patients rehabilitation.

A computerized list of individuals with brain injuries discharged from Leon S. Peters Rehabilitation Center was generated representing the fiscal years 1992 through 1994. Demographic information including age, race, sex, and length of stay was also generated from the computer data base. The list was analyzed and any individuals under the age of 17 or over the age of 80 were eliminated. Medical records of the remaining individuals were then analyzed to obtain the GCS score. The FIM scores in the areas of self-feeding skills, grooming, dressing, and transfers to the commode and into the tub or shower were obtained for those individuals with 
GCS scores through the occupational therapy patient files. These FIM scores were recorded. To ensure confidentiality, a number was assigned to each patient's data in place of patient's name.

A data base was formed with the GCS score and the discharge FIM scores. The GCS scores and the discharge FIM scores of individuals who sustained brain injuries were correlated using a multiple regression correlation via the SPSS statistical computer program using a significance of $\underline{p} \leq .05$. 
CHAPTER

ANAIYSIS OF DATA

The data for this ex post facto study utilizing a multiple regression correlation between the Glasgow Coma Scale (GCS) score and The Functional Independence Measure (FIM) score will be described in this chapter. The degree of correlation was used to determine the significance of the relationships between the level of consciousness (GCS score) and the level of function for activities of daily living (FIM scores).

subjects

The sample consisted of 38 individuals with brain injuries who received rehabilitation at Leon s. Peters Rehabilitation Center in Fresno, California during 1992 through 1994 fiscal years. The sample contained 31 males and 7 females (see Figure 2). The subjects' ages ranged from 17 to 72 years of age (see Figure 3). The mean age was 31.26 years of age and the standard deviation was 12.63 . Ethnic groups were represented in varying percentages (see Figure 2). The length of stay in Leon $S$. Peters Rehabilitation center for these individuals varied from 5 to 80 days (see Figure 4 ). The mean length of stay was 22.44 days with a standard deviation of 17.66 . 


\section{Figure 2}

\section{Male and Female Ethnic Representation}

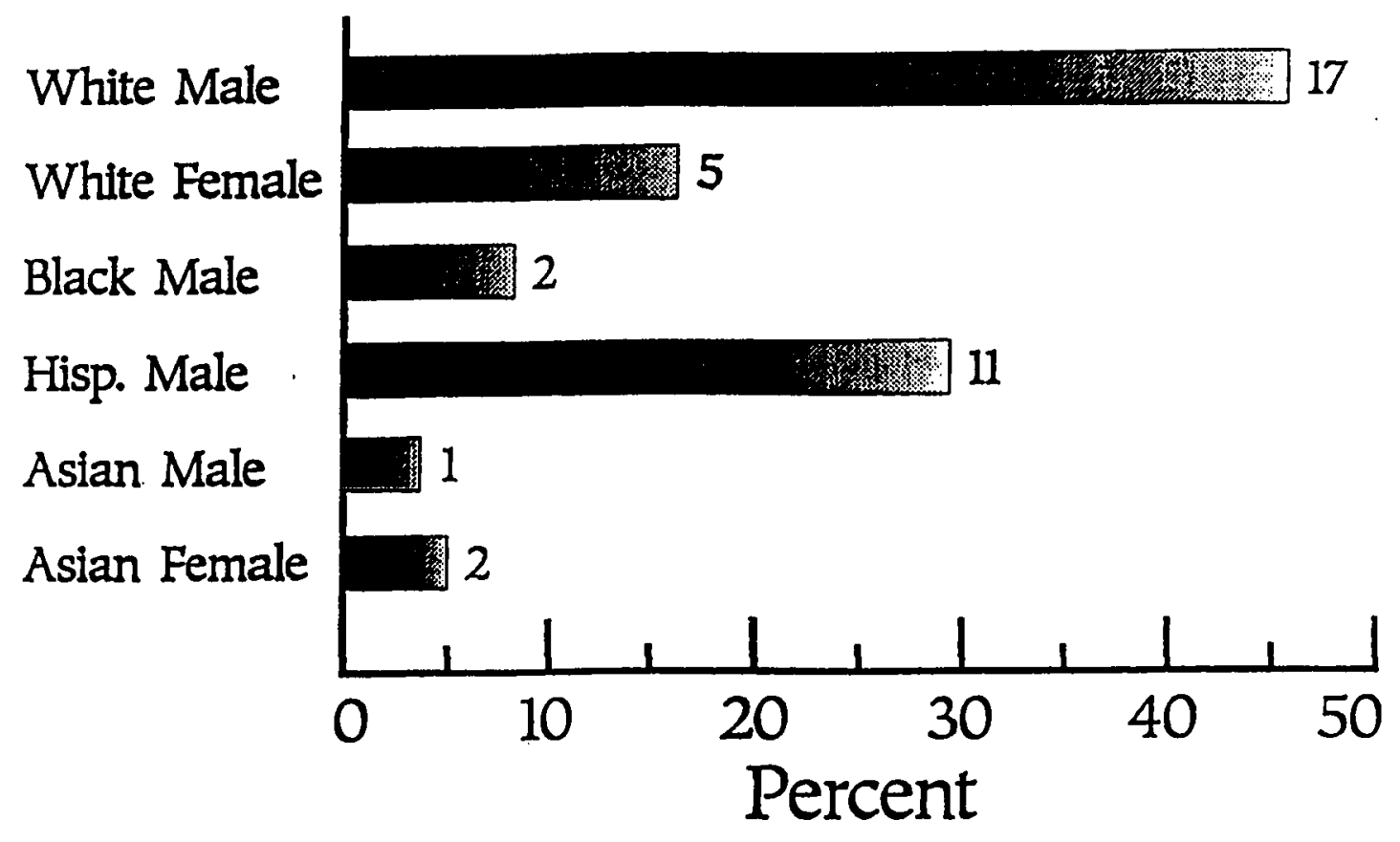


Figure 3

Age of Patients

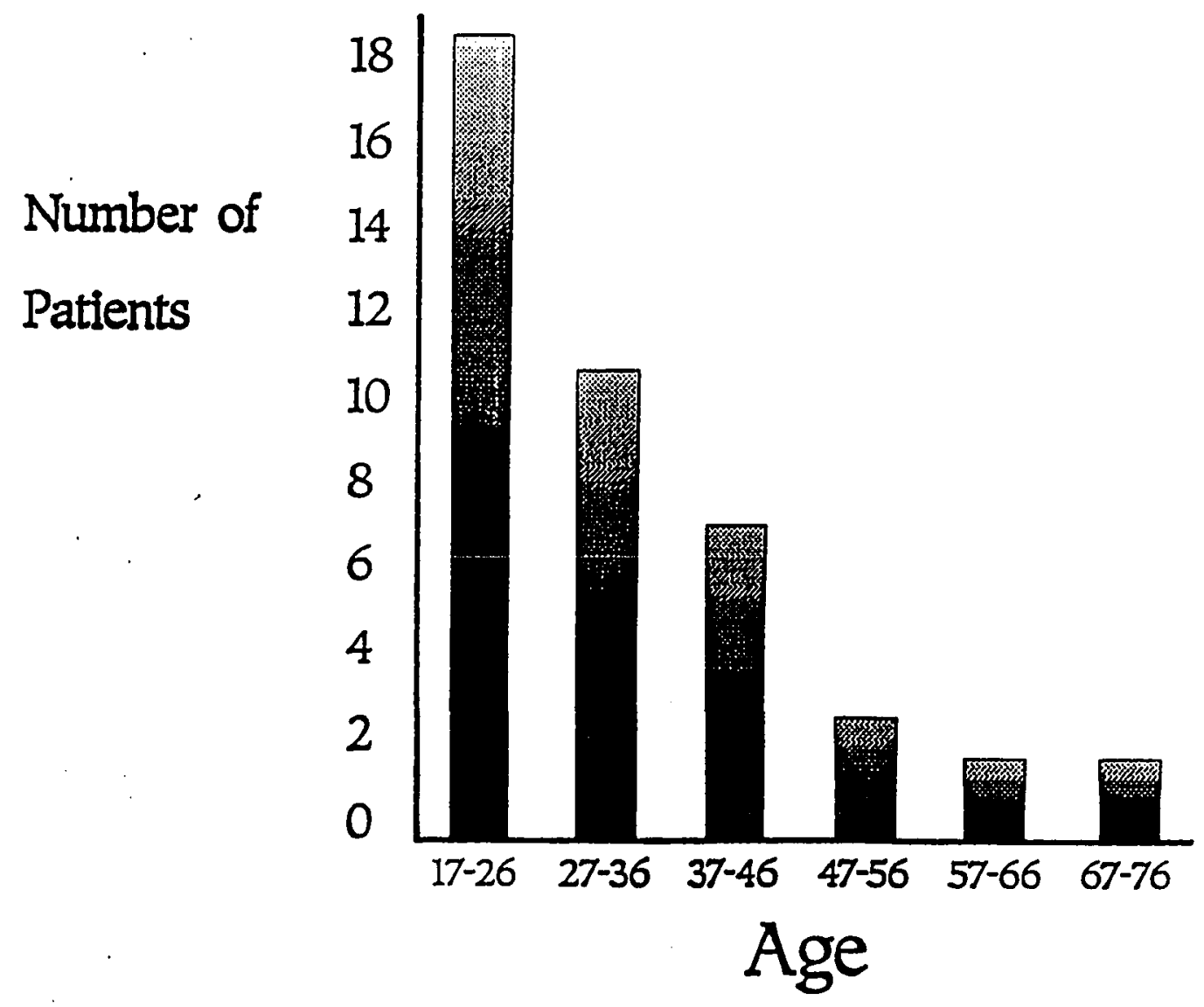


Figure 4

Length of Stay in Rehabilitation

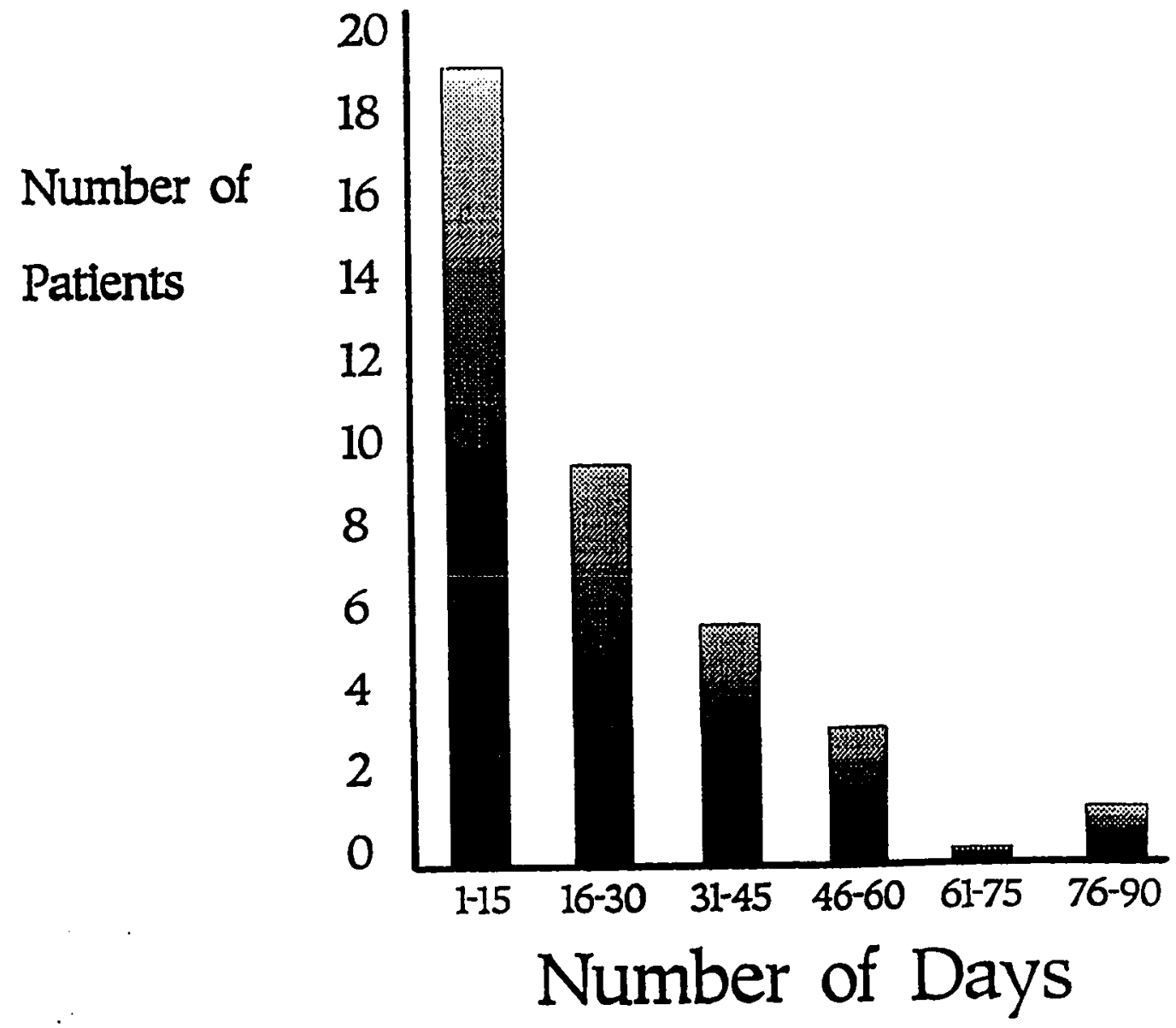


Research Questions

This study was conducted to determine the relationship between the Glasgow Coma Scale (GCS) score, established within 24 hours of an accident, and the Functional Independence Measure (FIM) score in the areas of self-care skills, which accounted for both physical and cognitive function.

Research question 1 was: What were the Glasgow Coma Scale scores for patients with brain injuries? The Glasgow Coma scale scores utilized in this study are presented in Figure 5.

Research question 2 was: In the sample studied, what were the Functional Independence Measure discharge scores in the areas of self-feeding, grooming, dressing, and bathroom transfers? The Functional Independence Measure scores and patient representation at each level of assistance for selfcare items of self-feeding skills, grooming, dressing upper body, dressing lower body, and transfer to the commode and into the tub or shower utilized in this study are illustrated in Figures 6 through 11. The mean and standard deviation for the GCS score, established within 24 hours of an accident, and The FIM scores in the areas of grooming, dressing, transfers to the commode and into the tub or shower, and self-feeding skills upon discharge from 
Figure 5

Glasgow Coma Scale (GCS) Representation

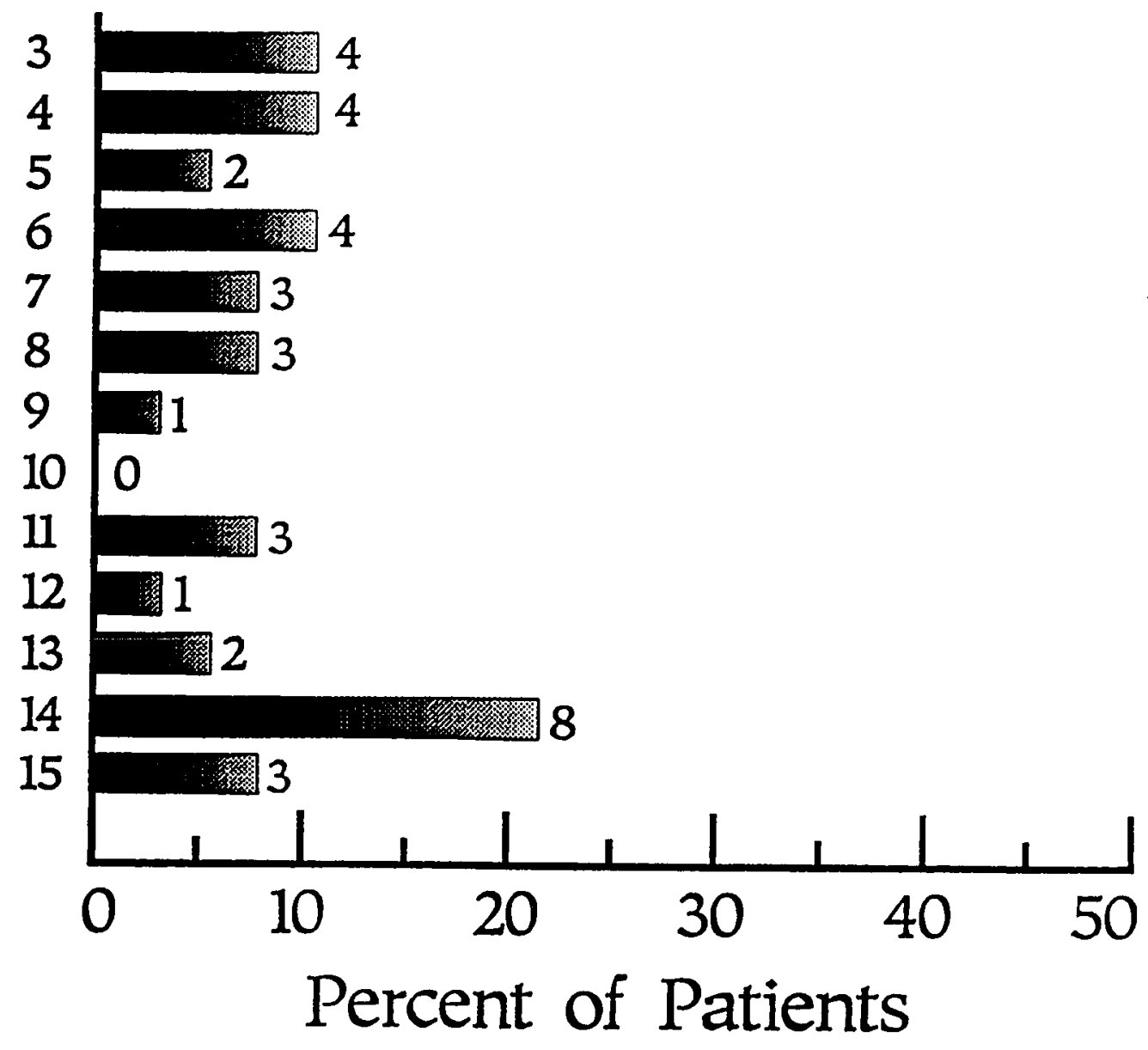




\section{Figure 6}

\section{Discharge FIM Scores for Self-Feeding}

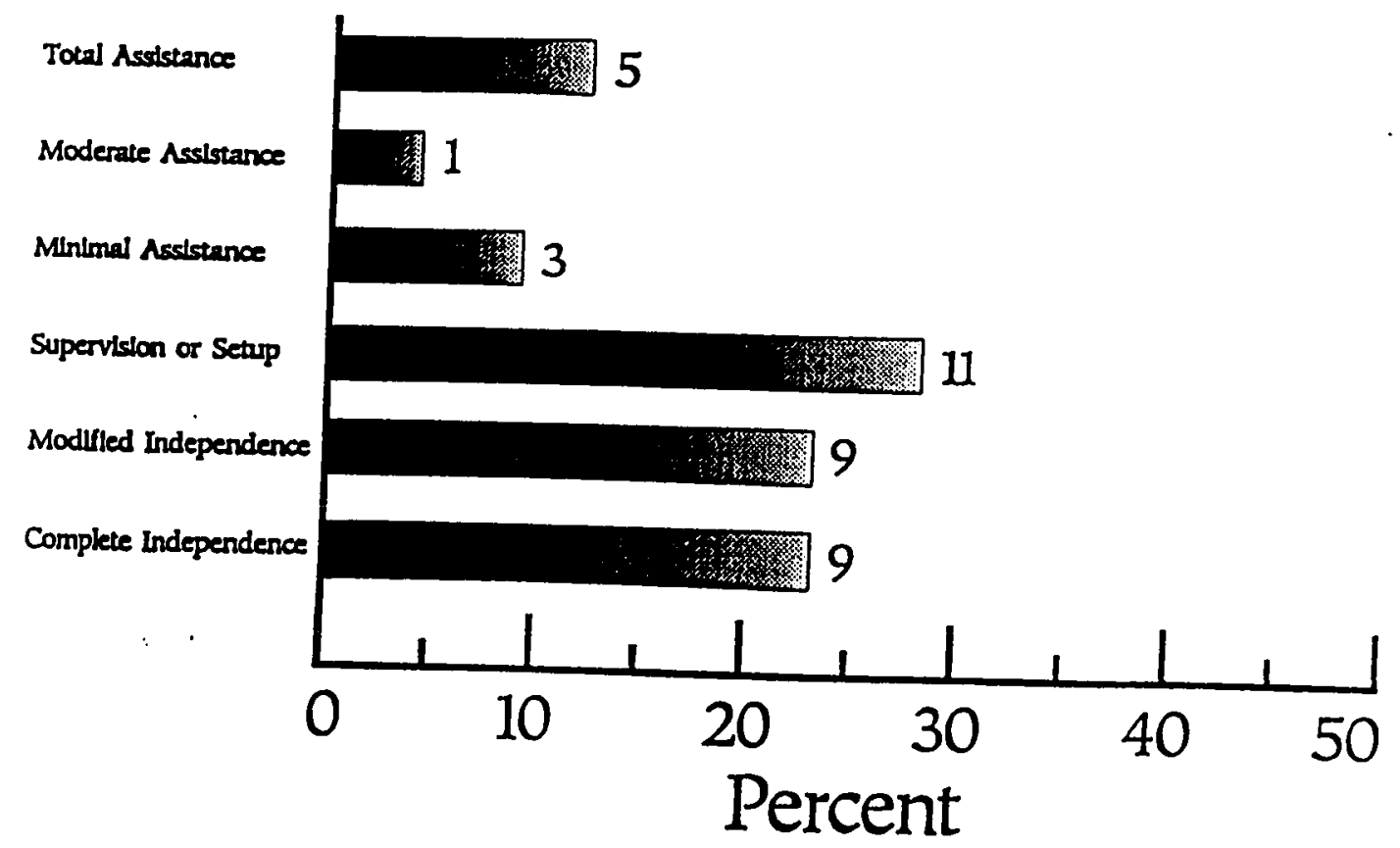


Figure 7

\section{Discharge FIM Scores for Grooming}

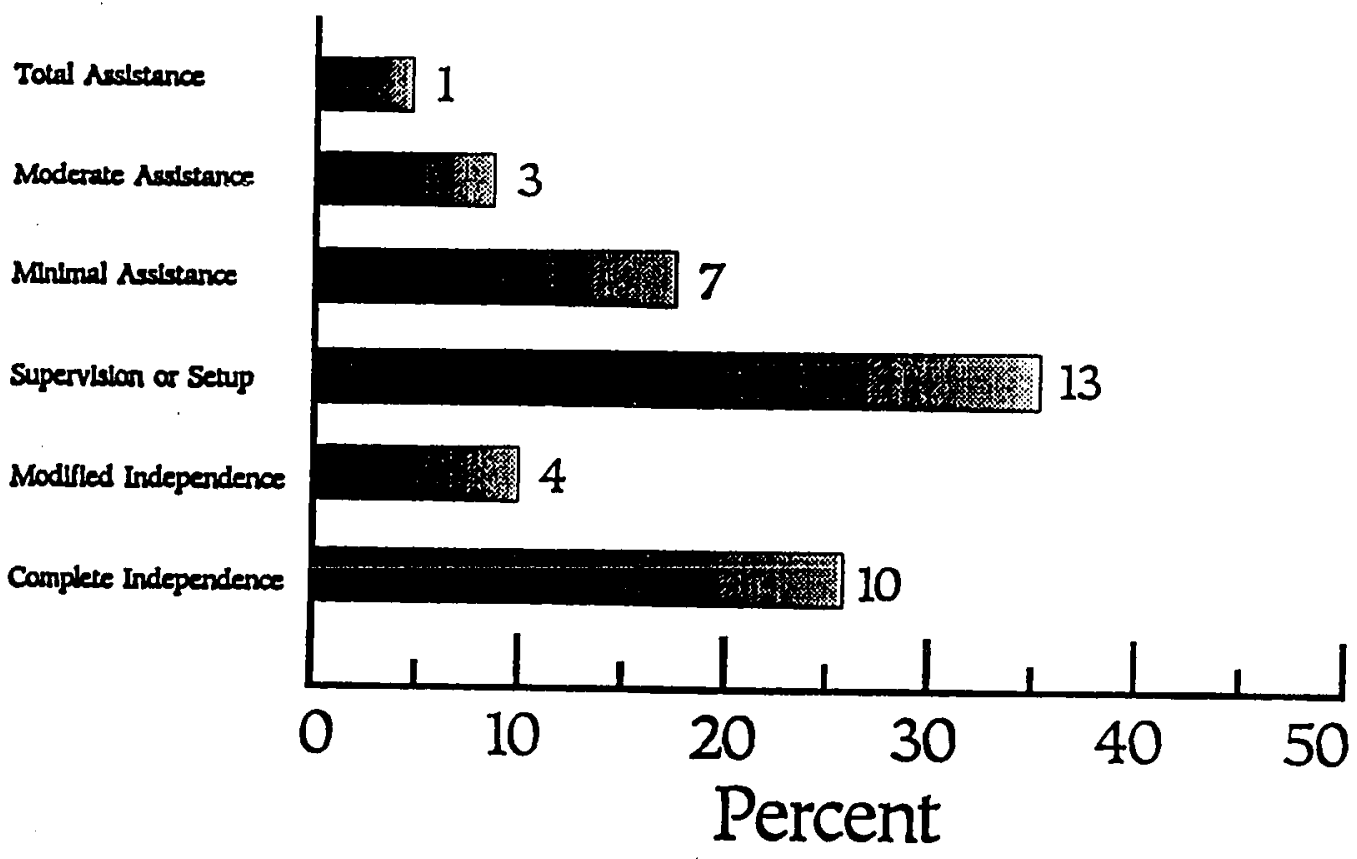


Figure 8

\section{Discharge FIM Scores for Upper Body Dressing}

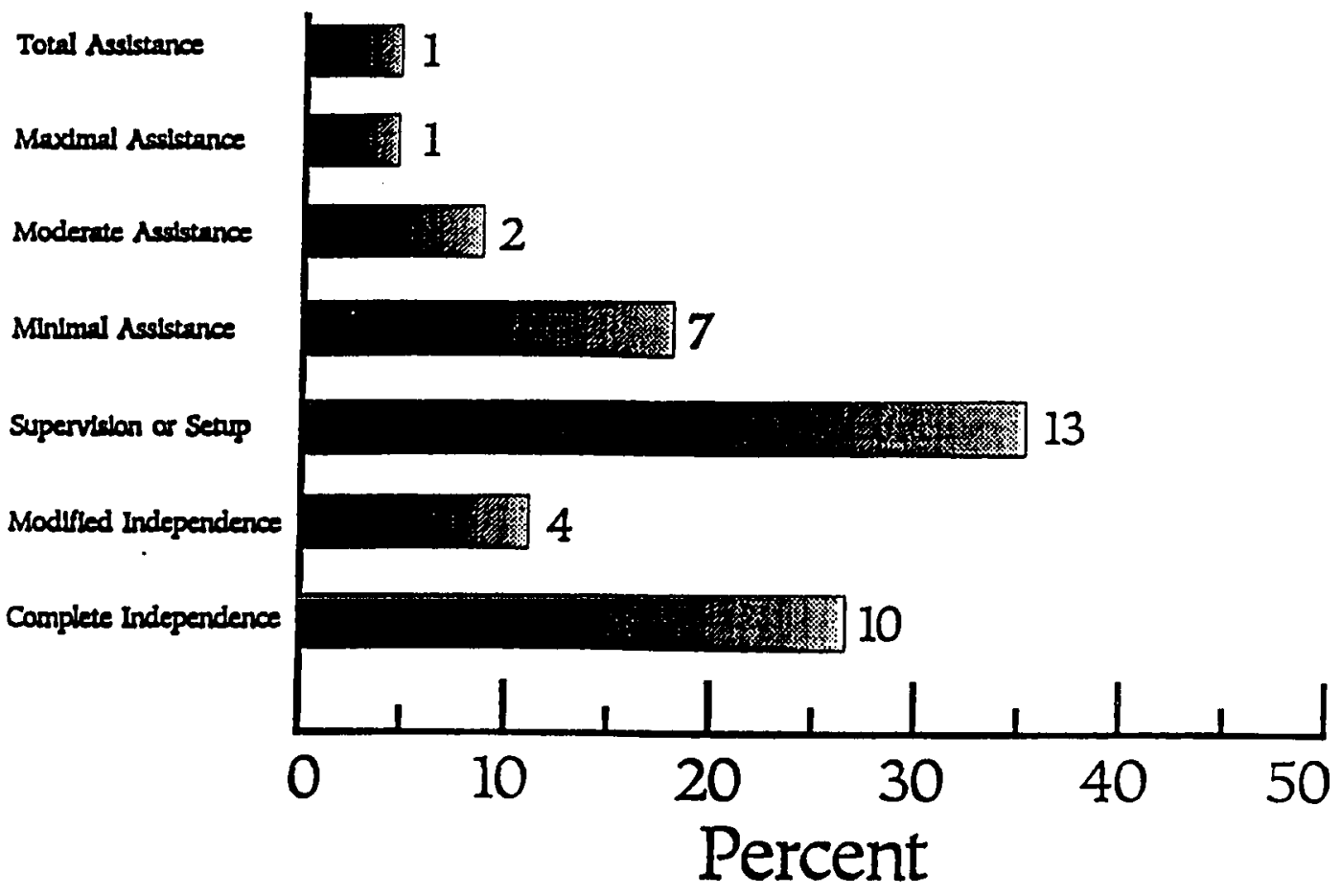


Figure 9

\section{Discharge FIM Scores for Lower Body Dressing}

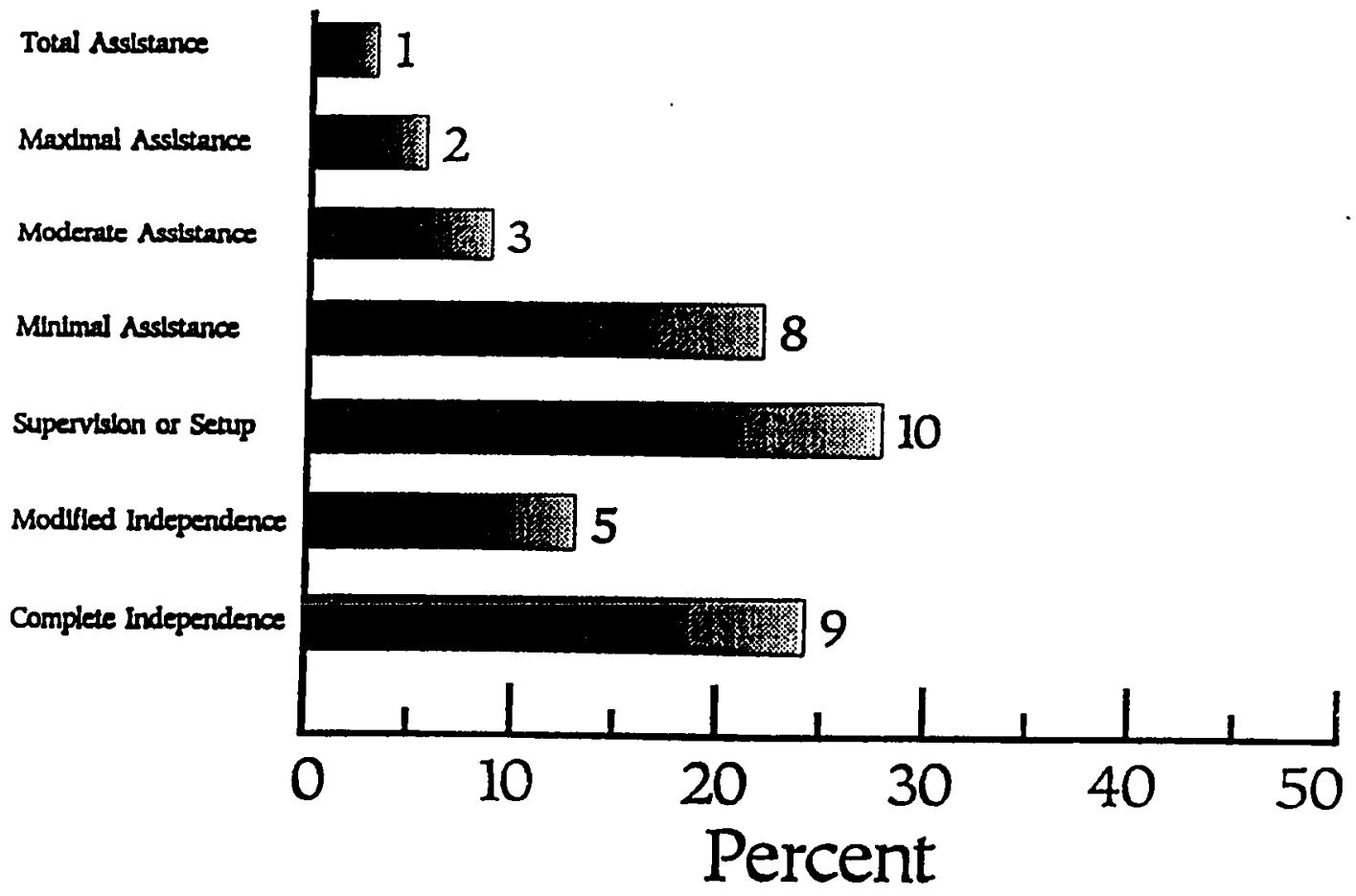




\section{Figure 10}

\section{Discharge FIM Scores for Commode Transfers}

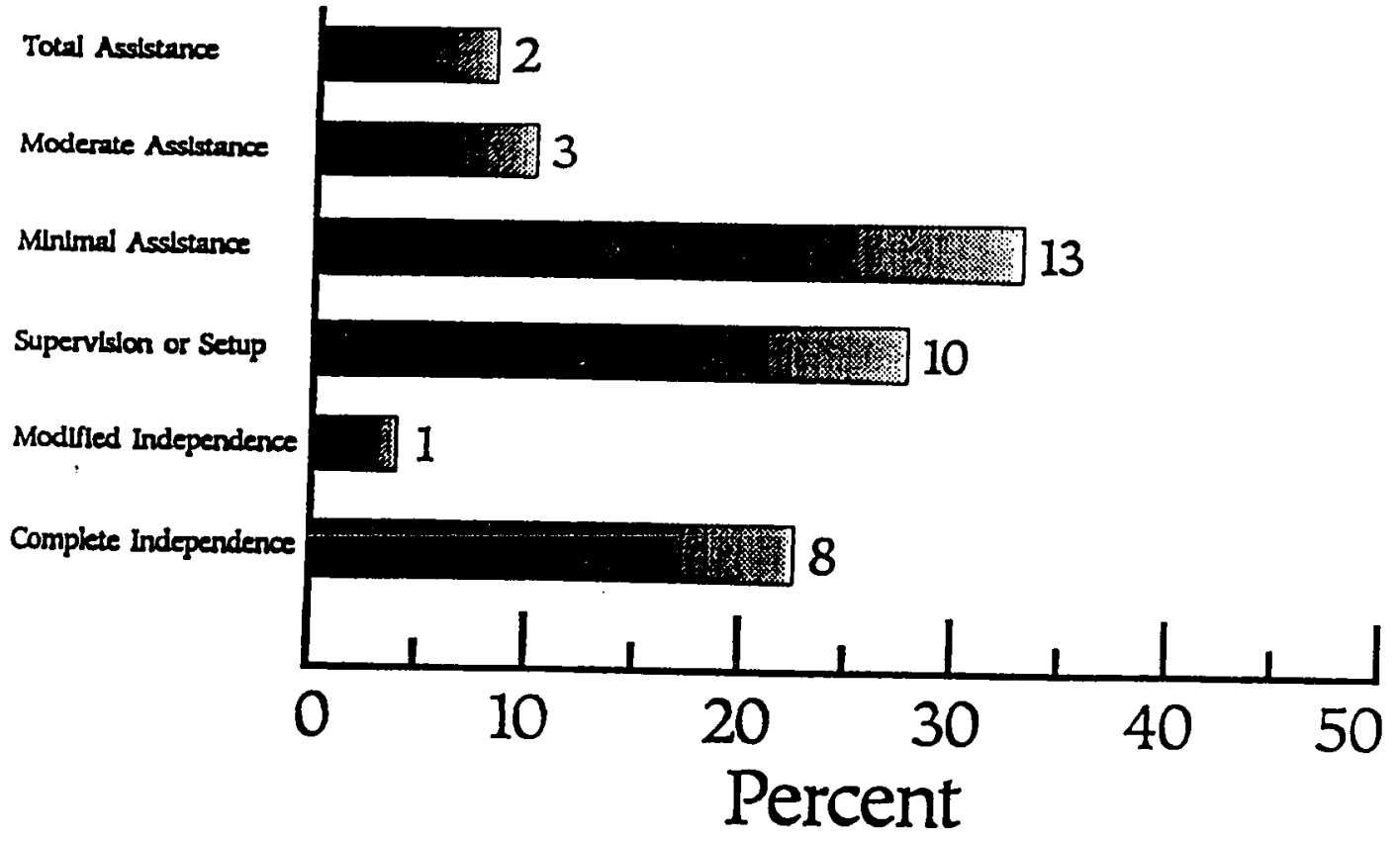


Figure 11

\section{Discharge FIM Scores for Transfers to Tub or Shower}

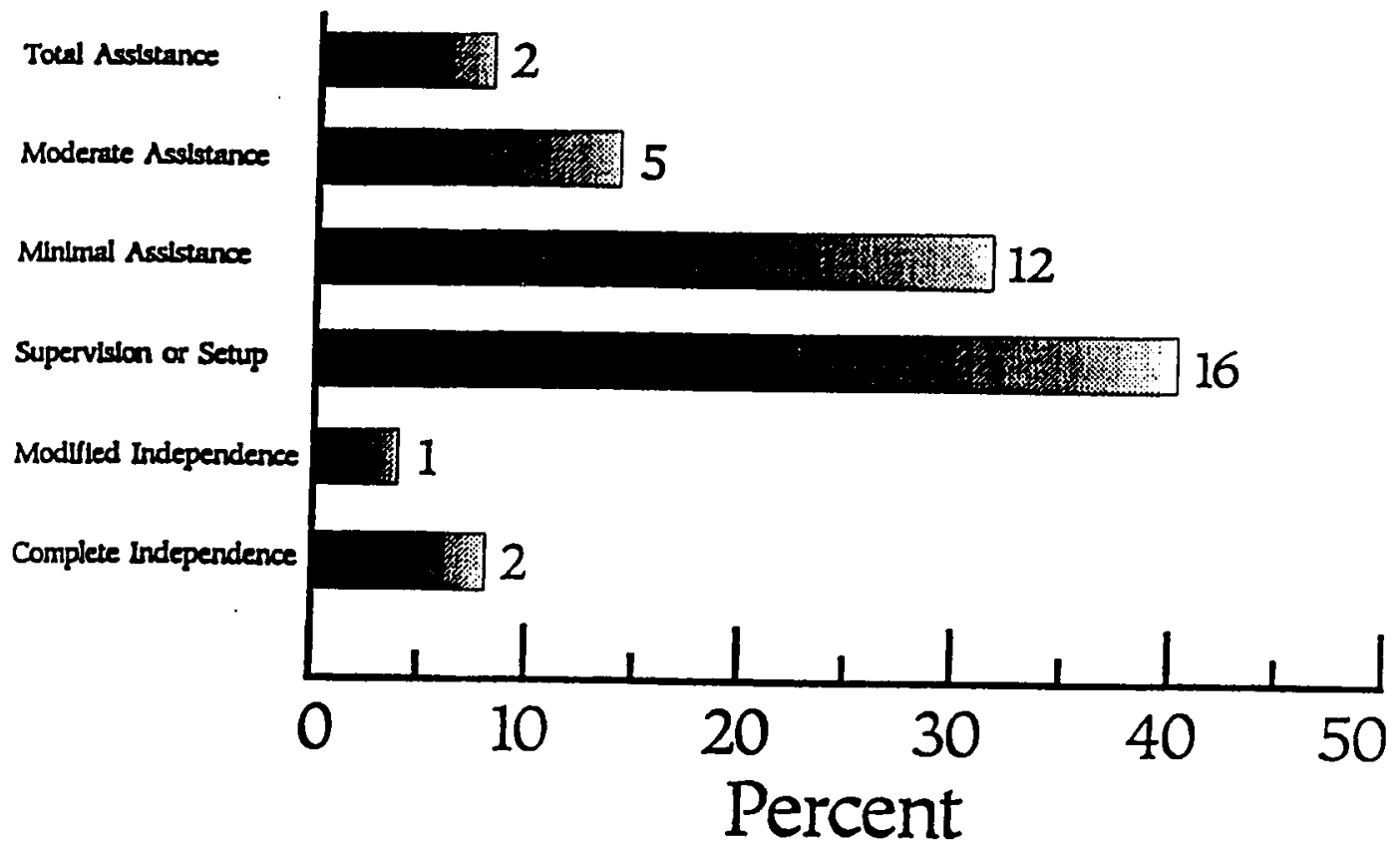


rehabilitation are presented in Table 1.

Research question 3 was: What was the relationship between the Glasgow Coma Scale level, established within 24 hours of an accident, and the Functional Independence Measure in specific daily living activities? The significance of the relationship between the Glasgow Coma Scale score and the Functional Independence Measure scores in specific daily living activities was established using multiple regression correlations and a significance level of $\mathfrak{p} \leq .05$. There was no significant relationship found between the GCS score and the FIM scores for specific daily living activities.

Research question 4 was: Could the Glasgow Coma Scale score predict the discharge scores of the Functional Independence Measure? Since no significant relationship was established between the GCS score and the FIM score, the Glasgow Coma Scale score was not found to be a valid predictor of the discharge scores on the Functional Independence Measure in this study. 
Table 1

Means and standard Deviations of the GCS and the FIM scores

Mean

standard Deviation

GCs

9.05

4.31

FIM

Grooming

5.18

1.44

Dressing- Upper Body

5.15

1.49

Dressing - Lower Body

4.97

1.60

Tub/Shower Transfers

4.34

1.23

Toilet Transfers

4.68

1.56

Self-Feeding

5.05

1.88 
CEAPIER 5

RESULTS, PROFESBIONAL IMPLICATIONS

RECOMMENDATIONS AND SUMMARY

The literature supports the premise that it is important to predict outcomes for survivors of severe brain injury to ensure the best course of treatment planning as well as decision making regarding rehabilitation and longterm care. There are many variables that affect the ability to predict the outcomes of severe brain injury survivors. These include duration of coma, age, pupillary responses, the presence of mass lesions requiring neurosurgery, elevated intracranial pressure, evoked potentials and various blood and cerebrospinal fluid factors.

"One of the major variables to predict outcome is severity of brain injury. Many studies have used the initial evaluation of the patients to predict outcome from brain injuries" (Spettell et al., 1991, p. 320). Included in the initial evaluation is a rating scale of the depth of coma at the time of admission or during the first 24 hours after trauma. The scale most often used is the Glasgow coma Scale (Spettell et al., 1991).

A correlational study performed by Choi, Narayan, Anderson, and ward (1988) found that of 21 variables studied, a combination of "age, motor response and pupillary 
response yield a compact yet highly predictive model" (p. 382). Heinemann, Linacre, Wright, Hamilton and Granger (1994) conducted a study investigating "the importance of several predictors of two kinds of rehabilitation outcome: independence in function at discharge and length of stay" (p. 133). The study utilized the FIM to indicate the functional status at admission and discharge. Heinemann et al. (1994) discovered that age, promptness of admission to rehabilitation, and frequency of rehabilitation interruptions were often significant predictors among neurological conditions. The areas most affected by these predictors were discharge cognitive function and length of stay .

Functional status upon admission was "consistent1y related to discharge function and length of stay. The strength of these associations varies across impairment groups" (Heinemann et al., 1994, p. 141). Heinemann et al. (1994) also stated that the "relative unimportance of cognition in predicting length of stay suggests that the kinds of goals that justify rehabilitation stays are more strongly determined by physical function than by cognitive function" (p. 142).

This study was conducted to determine the relationship between the Glasgow Coma Scale (GCS) score, established within 24 hours of an accident, and the Functional 
Independence Measure (FIM) scores in the areas of self-care skills, which accounted for both physical and cognitive function. A multiple regression correlation was utilized to determine the significance of the relationship between these two measures.

\section{Research Questions}

Research questions 1 and 2 identified the Glasgow Coma scale scores and the Functional Independence Measure scores for adults with brain injuries at Leon $s$. Peters Rehabilitation Center. The Glasgow Coma Scale score and Functional Independence Measure scores are outlined in chapter four (see Figure 5 through 11). There were no other studies identified in the literature review that compared the GCS scores and the FIM scores. This study determined that there was no significant relationship between these two measures.

Research question 3 was: What was the relationship between the Glasgow Coma Scale level, established within 24 hours of an accident, and the Functional Independence Measure in specific daily living activities? Upon examination of the data no significant relationships were established to support the use of the Glasgow coma scale score, established within 24 hours of the accident, as a valid predictor of the Functional Independence Measure, in the areas of self- 
feeding skills, grooming, dressing, and transfers to the commode and into the tub or shower upon discharge from rehabilitation. The data also revealed that there was no significant relationship between the GCS score and the FIM scores upon admission or the length of stay.

Research question 4 was: Could the Glasgow Coma Scale score predict the discharge scores of the Functional Independence Measure? This research supports the statement of Overgaard et al.'s (1973) statement, "Despite the well-recognized importance of early prognosis after severe head injury, we still do not have reliable guidelines upon which the outcome can be confidently predicted" (p. 7830). "When the brain is the organ affected, the persisting disability usually comprises both mental and physical handicaps which can seriously impair the quality of life" (Jennett \& Bond, 1975, p. 480). There are many variables that can contribute to predicting outcomes of individuals with brain injuries. As indicated by the previous studies mentioned a combination of variables gives a higher predictability of outcomes. The results of this study indicate that the GCS score alone was not a valid predictor of functional outcomes as measured by the FIM scores.

The GCS appears to be reliable for predicting short term outcomes rather than long term outcomes. The GCS is a good indicator of a patient's status at the scene of an 
accident and it also aids with documentation of early recovery. However, as Lyle et al. stated in 1986, "the capability of the Glasgow Coma scale to accurately reflect clinical improvement diminishes as the observation period extends from days to weeks" (p. 18). In this study the relationship between the GCS and the FIM indicates that the GCS score is not a predictor of functional or occupational long term outcomes of patients with brain injuries.

Implications for the Profession

In this study the outcomes in the areas of selffeeding, grooming, dressing, and transfers to the commode and into the tub or shower, which are most commonly rated by occupational therapists (Fricke, Unsworth, \& Worrell, 1992), did not appear to be related to the Glasgow Coma scale score for the subjects in this study. The occupational therapist should consider other factors besides the Glasgow Coma scale score when predicting functional or occupational outcomes of patients with brain injuries. Occupational therapists should be exploring and identifying other means in which to combine cognitive and physical function when predicting outcomes for individuals with brain injuries. 
Further Implications for Research

In order to rule out any possible significant relationship between the GCS and the FIM, a larger sample and subjects from multiple rehabilitation facilities would be needed.

A comparison study between the FIM and other outcome measures for individuals with brain injuries such as the Glasgow Outcome Scale and the Disability Rating scale could be conducted. Such a study could establish, if a set of scores could be utilized to facilitate more effective treatment planning. This would be useful in determining which tool is most reliable in predicting outcomes of individuals with brain injuries. Research could also be conducted on how different variables such as cultural and language barriers, multiple diagnoses, and location of the site of injury may affect individuals FIM scores at the time of discharge. 


\section{References}

Anderson, S. I., Housley, A. M., Jones, P. A., Stattery, J., \& Miller, J. D. (1993). Glasgow Outcome Scale: an inter-rater reliability study. Brain Injury, Z(4), 309317.

Bergman, T. A., Rockswold, G. L., Haines, S. J., \& Ford, S. E. (1987). Outcome of severe closed head injury in the midwest: A review and comparison with other major head trauma studies. Minnesota Medicine, 70, 397-401.

Byrnes, M. B. \& Powers, F. F. (1989). FIM: Its use in identifying rehabilitation needs in the head-injured patient. Journal of Neuroscience Nursing, 21(1), 61-63. Changaris, D. G., McGraw, C. P., Richardson, J. D., Garretson, H. D., Arpin, E. J., \& Shields, C. B. (1987). Correlation of cerebral perfusion pressure and glasgow coma scale to outcome. The Journal of Trauma, 27, 10071013.

Choi, S. C., Muizelaar, J. P., Barnes, T. Y., Marmarou, A., Brooks, D. M., \& Young, H. F. (1991). Prediction tree for severely head-injured patients. Journal of Neurosurgery, 75, 251-255.

Choi, S. C., Narayan, R. K., Anderson, R. L., \& Ward, J. D. (1988). Enhanced specificity of prognosis in severe head injury. Journal Neurosurgery, 69, 381-385.

Davidoff, G. N., Roth, E. J., Haughton, J. S., \& Ardner, M. 
S. (1990). Cognitive dysfunction in spinal cord injury patients: Sensitivity of the functional independence measure subscales vs neuropsychologic assessments. Archives of Physical Medicine and Rehabilitation, 71, 326-329.

Di Scala, C., Grant, C. C., Brooke, M. M., \& Gans, B. M. (1992, June). Functional outcome in children with traumatic brain injury. American Journal of Physical Medicine and Rehabilitation, 71, 145-148. Fleming, J., Thy(Hons), B., 7 Maas, F. (1994). Prognosis of rehabilitation outcome in head injury using the disability rating scale. Archives of physical Medicine and Rehabilitation, 74, 156-163.

Fricke,J., Unsworht, C., \& Worrell, J. (1993). Reliability of the functional independence measure with occupational therapists. The Australian Occupational Therapy Journal, 40, 7-15.

Giacino, J. T., Kezmarsky, M. A., Deluca, J., \& Cicerone, K. D. (1991). Monitoring rate of recovery to predict outcome in minimally responsive patients. Archives of Physical Medicine and Rehabilitation, 72, 897-901. Gothoh, O., Tamura, A., Oka, H., Tsujita, Y., Sano, K., Yasui, N., Suzuki, A., Hadeishi, H., Nihei, H., \& Manaka, S. (1993). Acute aneurysm surgery and the glasgow coma scale: Relationship with 6-month outcome. Neurological 
Surgery, $\underline{21}(1), 37-43$.

Granger, C. V., Cotter, A. C., Hamilton, B. B., \& Fiedler, R. C. (1990). Functional assessment scale: A study of persons with multiple sclerosis. Archives of Physical Medicine and Rehabilitation, 71, 870-875. Granger, C. V., cotter, A. C., Hamilton, B. B., \& Fiedler, R. C. (1993). Functional assessment scales a study of persons after stroke. Archives of Physical Medicine and Rehabilitation, 74, 133-138.

Granger, C. V., \& Hamilton, B. B. (1993). The uniform data system for medical rehabilitation report of first admissions for 1991. American Journal of Physical Medicine and Rehabilitation, 72(1), 33-38. Granger, C. V., Hamilton, B. B., Kieth, R. A., Zielezny, M., \& Sherwin, F. S. (1986). Advances in functional assessment for medical rehabilitation. Topics in Geriatric Rehabilitation, $1(3), 56-74$. Granger, C. V., Hamilton, B. B., Linacre, J. M., Heinemann, A. W., \& Wright, B. D. (1993). Performance profiles of the functional independence measure. American Journal of Physical Medicine and Rehabilitation, 72(2), 84-89. Guide for use of the uniform data set for medical rehabilitation (Adult FIM), Version 4.0. Buffalo, New York 14214: State University of New York at Buffalo. 
Heinemann, A. W., Linacre, J. M., Wright, B. D., Hamilton, B. B., \& Granger, C. V. (1993). Relationships between impairment and physical disability as measured by the functional independence measure. Archives of Physical Medicine and Rehabilitation, 74, 566-573.

Heinemann, A. W., Linacre, J. M., Wright, B. D., Hamilton, B. B., \& Granger, C. V. (1994). Prediction of rehabilitation outcomes with disability measures. Archives of physical Medicine and Rehabilitation, 75, $133-143$

Jennett, B., \& Bond, M. (1975). Assessment after severe brain damage: A practice scale. The Lancet, $i, 480-484$. Jennett, B., Teasdale, G., Braakman, R., Minderhound, J., Heiden, J., \& Kurze, T. (1979). Prognosis of patients with severe head injury. Neurosurgery, 4(4), 283-289. Jennett, B., \& Teasdale, G. (1981). Management of Head Injuries. Philadelphia: F. A. Davis. Levin, S. H., Gary, H. E., \& Eisenberg, H. M. (1989). Duration of impaired consciousness in relation to side of lesion after severe head injury. The Lancet, $i$, 10011003.

Lyle, D. M., Pierce, J. P., Freeman, E. A., Bartrop, R., Dorsch, N. W., Fearnside, M.R., Rushworth, R. G., \& Grant, J. M. (1986). Clinical course and outcome of severe head injury in Australia. Journal of 
Neurosurgery, 65, 15-18.

Murray, L. S., Teasdale, G. M., Murray, G. D., Jennett, B., Miller, J. D., Pickard, J. D., Shaw, M. D., Achilles,J., Bailey, S., Jones, P., Kelly, D., \& Lacey, J. (1993). Does prediction of outcome alter patient management? The Lancet, i, 1487-1491.

Overgaard, J., Christensen, S., Hvid-Hasen, O., Haase, J., Land, A., Hein, O., Pedersen, K. K., \& Tweed, W. A. (1973). Prognosis after injury based on early clinical examination. The Lancet, ii, 631-635.

Reed, K. I. (1984). Models of practice in occupational therapy. Baltimore, MD: Williams \& Wilkins.

Rimel, R. W., \& Tyson, G. W. (1979). The neurologic examination in patients with central nervous system trauma. Journal of Neurosurgical Nursing, 11, 62-69. Sacco, R. L., Vangool, R., Mohr, J. P., \& Hauser, W. A. (1990). Nontraumatic coma : Glasgow coma score and coma etiology as predictors of 2-week outcome. Archives of Neurology, 47, 1181-1184.

Selladurai, B. M., Jayakumar, R., Tan, Y. Y., \& Low, H. C. (1992). Outcome prediction in early management of severe head injury: an experience in Malaysia. British Journal of Neurosurgery, $6,549-557$.

Smith, S. S., \& Winkler, P. A. (1990). Traumatic head injuries. In D. A. Umphred (Ed.), Neurological 
Rehabilitation (2nd ed., pp.347-396). St. Louis: Mosby.

Spettell, C. M., Ellis, D. W., Ross, S. E., Sandel, M. E., o'Malley, K. F., Stein, s. C., Spivack, G., \& Hurley, K. E. (1991). Time of rehabilitation admission and severity of trauma: Effect on brain injury outcome. Archives of Physical Medicine and Rehabilitation, 72, 320-325.

Spivack, G., Spettell, C. M., Ellis, D. W., \& Ross, S. E. (1992). Effects of intensity of treatment and length of stay on rehabilitation outcomes. Brain Injury, $\underline{6}(5)$, 419-434.

Starmark, J. E., Stalhammar, D., Holmgren, E., \& Rosander, B. (1988). A comparison of the glasgow coma scale and the reaction level scale (RLS85). Journal of Neurosurgery, 69, 699-706.

Taheri, P. A., Karamanoukian, H., Gibbons, K., Waldman, N., Doerr, R. J., \& Hoover, E. L. (1993). Can patients with minor head injuries be safely discharged home?. Archives of Surgery, 128, 289-292.

Teasdale, G., \& Jennett, B. (1974). Assessment of coma and impaired consciousness: A practical scale. The Lancet, ii, $81-84$. 
Teasdale, G., Jennett, B., Murray, L., \& Murray, G. (1983). Glasgow Coma Scale: To sum or not to sum?. The Lancet, i. 678 .

Waxman, K., Sundinem M. J., \& Young, R. F. (1991). Is early prediction of outcome in severe head injury possible?. Archives of Surgery, 126, 1237-1242. Whitlock, J. A., Jr. (1992). Functional outcome of lowlevel traumatically brain-injured admitted to an acute rehabilitation programme. Brain Injury, $6,447-459$. 
APPENDICES 


\section{APPENDIX A \\ Letter of permission for utilization of the Glasgow Coma scale}


Prof. Bryan Jennett

University Dept. of Neurosurgery,

Institute of Neurological Science,

Southern Genera Hospital.

Glasgow G51 4TF

\section{Dear Professor Jennett:}

I am presently working on my Masters degree in occupational

tharapy from San Jose State University of California. I am

writing to request permission to utilize the Glasgow coma Scale

(GCS) as part of my master's thesis.

I plan to complete a study analyzing the relationship between the Glasgow Coma scale and functional independence in activities of daily living of brain injured adults. The GCS will be correlated to the Functional Independence Measures used by the Leon $S$. Peter Rehabilitation Center.

If any questions arise concerning my use of the GCS in this study please contact me at the above address. Thank you.

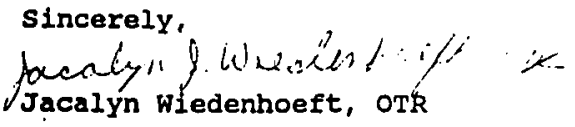

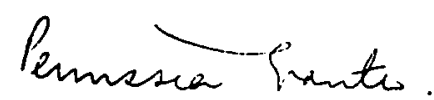

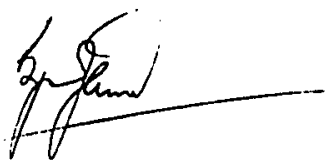


APPENDIX B

Glasgow Coma scale 


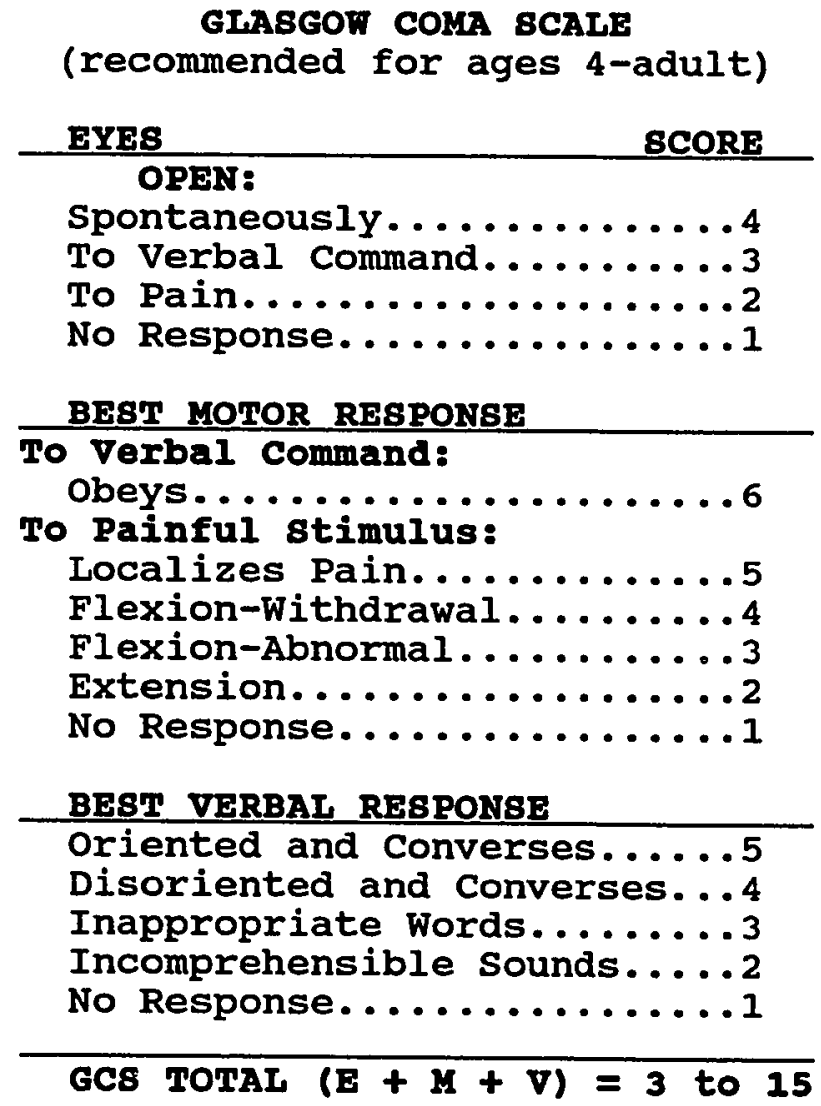


1. Eye Opening

The minimum stimulus sufficient to cause opening of one or both eyes is determined. If the patient is physically prevented from opening either eye (bandage or lid swelling), the letter "E" is recorded after the total Glasgow Coma Scale score.
A. Eyes open spontaneously (4 points)
B. Eyes open to speech ( 3 points): The command to open the eyes is an acceptable stimulus, as is calling the patient's name.

C. Eyes open to noxious stimuli (2 points): The stimulus applied may be the same as that used to determine the best motor response.

D. No eye opening ( 1 point)

\section{Best Motor Response}

The examiner determines the best response that the patient can make with either arm.

A. Obeys commands (6 points): The patient, once aroused, raises an arm on request or holds up a specified number of fingers. Requests to grasp the examiner's fingers are unreliable because of "tonic grasp" reflexes. However, ordering the patient to release his grip does constitute a valid test.

B. Localized noxious stimulus ( 5 points): The patient fails to obey commands, but moves either arm toward a 
noxious cutaneous stimulus and eventually "finds" it with his hand. The stimulus should be maximal in intensity and should vary in site of application beginning with the arms and moving to the trunk (pinch trapezius muscle; apply knuckle to sternum) in order to exclude stereotyped flexor movements.

C. Flexion withdrawal (4 points): In response to a noxious stimulus, the patient briskly flexes either arm but does not manually localize the irritant.

D. Abnormal flexion ( 3 points): In response to a noxious stimulus, the patient slowly adducts his shoulder, flexes and pronates his arm, flexes his wrist, and make a fist.

E. Abnormal extension (2 points): The patient adducts and internally rotates at his shoulder, extends his forearm, flexes his wrist, and makes a fist.

F. No motor response (1 point): To be accurate, however, the examiner must exclude spinal cord injury and be sure that his stimulus is sufficiently noxious.

3. Best Verbal Response

The best response that a patient can make after being maximally aroused (by noxious stimuli if necessary) is determined. If the patient cannot respond because of intubation, oral injuries, or dysphasia, this test category is omitted and the letter "V" is placed after 
the total score from the other two test categories.

A. Oriented ( 5 points): Implies awareness of self and the environment patient can correctly relate who he is, where he is, the year, and the month.

B. Confused Conversation ( 4 points): The patient is conversant but responses to questions indicate varying degrees of disorientation and confusion. It is here that verbatim reporting of the individual patient's responses can be useful.

C. Inappropriate Words ( 3 points): The patient cannot be engaged in sustained conversation, but utters intelligible words in an exclamatory (Curses) or disorganized manner.

D. Incomprehensible sounds ( 2 points): The patient makes sounds (moaning or groaning) that are not recognizable as words.

E. No Vocalization (1 point): The patient utters no sounds even in response to noxious stimuli. The score from each of the three test categories are added in order to determine the total Glasgow Coma scale score. Provided that all three categories can be evaluated, possible score range from three to 15 (Teasdale \& Jennett, 1974; Rimel \& Tyson, 1979). 


\section{APPENDIX C \\ Letter of permission for utilization of the \\ Functional Independence Measure}


UNIVERSITY AT BUFFALO

STATE UNIVERSTTY OF NEW YORK
Center for Functional Assessment Researeh Department of kithabilital in Medicine ivinan Sirvet Butlilu, New loth 14215.300.

FAN 1016) 829.2070

September 30, 1994

Jacalyn Wiedenhoeft, OTR

Leon S. Peters Rehabilitation Center

Community Hospitals of Central California

P. O. Box 1232

Fresno, CA 93715

Dear Ms. Wiedenhoeft,

Thank you for your request for perwission to reproduce pages 16 through 35 of Section III from Guide for the Uniform Data Set for Medical Rehabilitation (Adult FIM), Ve'rsion 4.0 as part of a thesis project, entitled $A$ Correlational Study Between the Glasgow Coma Scale and the Functional Independence Measure of Adult Individuals with Brain lijurles. for completion of your masters degree from San Jose State University. Permission is hereby granted to use those specific copyrighted parts of Version 4.0.

Please use the following citation:

Guide for the Uniform Data Sel for Medical Rehabilitation (Adult FIM), Version 4.0 Buffalo, NY 14214: State University of New York at Buffalo; 1993.

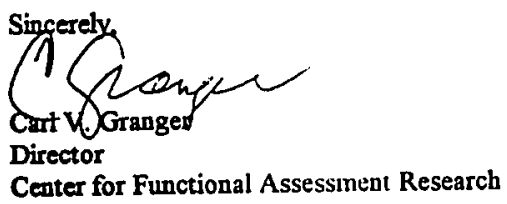


APPENDIX D

Functional Independence Measure 
Coding the Data Set (continued)

22. Functional Independence Measure (FIM)

\author{
PROCEDURES FOR SCORING THE \\ FUNCTIONAL INDEPENDENCE MEASURE (FIM)
}

Record the number which best describes the subject's level of function for every FIM item on the coding sheet. If the subject would be put at risk for Injury if tested. then enter 1. Leave no FIM item blank.

Each of the 18 items comprising the FIM has a maximum score of 7. and the lowest score on each item is 1 . The highest total score is 126 and the lowest total score is 18.

The cliniclans in the field have been adamant in their conviction that a seven-level scale is necessary for showing patient function change with sufficient sensitivity. The original four-level scale was superseded in 1987 and the seven-level scale is recommended for all items.

In the event FIM scores are rated higher during therapy than when the patient is observed on the nursing floor or in his/her room. record the lower score. The usual reason for this is the patient has not mastered the function or is too tired or not motivated enough to transfer the behavior out of the therapy setting. The lower score is recorded because it is what the patient actually, usually does. There may be a need to resolve the question of what is "usual" by discussion between therapist and nurse.

When two helpers are required in order for the patient to perform the behaviors described in an item, enter level 1 . Set-up is uniformly scored a level 5 for all items.

Comment: The social cognition items: social interaction. problem solving, and memory, are estimates of function in three important areas of a person's dally activity. Unlike the other areas of function assessed with the FIM, which have been in clinical use for years, consensus is not yet clear among behaviorists and rehabilitation clinicians about how to quantify these activities at the level of disability. The social cognition items in the FIM have very acceptable reliability. They have been refined as a result of comments made by users during the trial and implementation phases and will continue to be refined as more clinical and research experience is gained by the field. 
Functional Independence Measure - FIM (continued)

\section{DESCRIPTION OF THE LEVELS OF FUNCTION AND THEIR SCORES}

INDEPENDENT--- Another person is not required for the activity (NO HELPER).

7 Complete Independence--All of the tasks described as making up the activity are typically performed safely. without modification. assistive devices. or aids, and within reasonable time.

6 Modifled Independence--Activity requires any one or more than one of the following: An assistive device. more than reasonable time, or there are safety (risk) considerations.

DEPENDENT--- Another person is required for either supervision or physical assistance in order for the activity to be performed. or it is not performed (REQUIRES HELPER).

---MODIFIED DEPENDENCE---The subject expends half (50\%) or more of the effort. The levels of assistance required are:

5 Supervision or Setup--subject requires no more help than standby. cuing or coaxing. without physical contact. Or, helper sets up needed items or applies orthoses.

4 Minimal Contact Assistance--with physical contact the subject requires no more help than touching, and subject expends $75 \%$ or more of the effort.

3 Moderate assistance--subject requires more help than touching. or expends half $(50 \%)$ or more (up to $75 \%$ ) of the effort.

--COMPLETE DEPENDENCE---The subject expends less than half less than $50 \%$ ) of the effort. Maximal or total assistance is required. or the activity is not performed. The levels of assistance required are:

2 Maximal Assistance--subject expends less than $50 \%$ of the effort. but at least $25 \%$.

1 Total Assistance--subject expends less than $25 \%$ of the effort.

March 1, 1990

Copyright 1990 Research Foundation - State University of New York -17- Guide to the Uniform Data Set 
Functional Independence Measure - FIM (continued)

A: EATING Includes use of suitable utensils to bring food to the mouth. chewing and swallowing, once the meal is appropriately prepared.

\section{NO HELPER}

7. Complete Independence--Eats from a dish. while managing all consistencies of food, and drinks from a cup or glass with the meal presented in the customary manner on a table or tray. The subject uses a spoon or fork to bring food to the mouth: food is chewed and swallowed.

6. Modified Independence--Requires an adaptive or assistive device such as a straw. spork. rocking knife, requires more than a reasonable time to eat, or requires modified food consistency or blenderized food. or there are safety considerations. If the individual relies in part on other means of alimentation. such as parenteral or gastrostomy feedings. then he/she administers the feedings him/herself.

\section{HELPER}

5. Supervision or Setup--Requires supervision (e.g.. standing by. cuing. or coaxing) or setup (application of orthoses): or another person is required to open contalners. cut meat, butter bread, or pour liquids.

4. Minimal Contact Assistance--Subject Performs 75\% or more of feeding tasks.

3. Moderate Assistance--Performs $50 \%$ to $74 \%$ of feeding tasks.

2. Maximal Assistance--Performs $25 \%$ to $49 \%$ of feeding tasks.

1. Total Assistance--Performs less than $25 \%$ of feeding tasks. Or, the individual does not eat or drink full meals by mouth but must rely in part on other means of alimentation, such as parental or gastrostomy feedings. and does not administer the feedings him/herself. 
Functional Independence Measure - FIM (continued)

B: GROOMING Includes oral care. hair grooming. washing hands and face. and either shaving or applying makeup. If there is no preference for shaving or applying make-up. then disregard.

\section{NO HELPER}

7. Complete Independence--Cleans teeth or dentures, combs or brushes hair. washes hands and face. shaves or applies makeup. including all preparations.

6. Modifled Independence--Requires specialized equipment (including prosthesis or orthosis) or takes more than a reasonable time, or there are safety considerations.

\section{HELPER}

5. Supervision or Setup--Requires supervision (e.g.. standing by, cuing. or coaxing) or setup (application of orthoses, setting out grooming equipment. and initlal preparation such as applying toothpaste to brush, opening makeup containers).

4. Minimal Contact Assistance--Subject performs $75 \%$ or more of grooming tasks.

3. Moderate Assistance--Performs $50 \%$ to $74 \%$ of grooming tasks.

2. Maximal Assistance--Performs $25 \%$ to $49 \%$ of grooming tasks.

1. Total Assistance--Performs less than $25 \%$ of grooming tasks. 
Functional Independence Mcasurc - FM (continued)

C: BATHING Includes bathing the body from the neck down (excluding the back). either tub, shower or sponge/bed bath. Performs safely.

\section{NO HELPER}

7. Complete Independence--Bathes and dries the body.

6. Modifled Independence--Requires specialized equipment (including prosthesis or orthosis) or takes more than a reasonable time or there are safety considerations.

\section{HELPER}

5. Supervision or Setup--Requires supervision (e.g.. standing by, or cuing or coaxing) or setup (setting out bathing equipment, and initial preparation such as preparing the water or washing materials).

4. Minimal Contact Assistance--Subject performs $75 \%$ or more of bathing tasks.

3. Moderate Assistance--Performs $50 \%$ to $74 \%$ of bathing tasks.

2. Maximal Assistance--Performs $25 \%$ to $49 \%$ of bathing tasks.

1. Total Assistance--Performs less than $25 \%$ of bathing tasks. 
Functional Independence Mcasure - FIM (continued)

\section{D: DRESSING - UPPER BODY Includes dressing above the waist as well as donning and removing prosthesis or orthosis when applicable.}

\section{NO HELPER}

7. Complete Independence--Dresses and undresses including obtaining clothes from their customary places such as drawers and closets: manages bra. pull-over garment, and front-opening garment: manages zippers. buttons. and snaps: dons and removes prosthesis or orthosis when applicable.

6. Modified Independence--Requires special adaptive closure such as velcro, or assistive device (including a prosthesis or orthosis), or takes more than a reasonable time.

\section{HELPER}

5. Supervision or Setup--Requires supervision (e.g.. standby, cuing. or coandng) or setup (application of orthosis, setting out clothes or dressing equipment).

4. Minimal Contact Assistance--Subject performs $75 \%$ or more of dressing tasks.

3. Moderate Assistance--Performs $50 \%$ to $74 \%$ of dressing tasks.

2. Maximal Assistance--Performs $25 \%$ to $49 \%$ of dressing tasks.

1. Total Assistance--Performs less than $25 \%$ of dressing tasks, or is not dressed.

Copynght 1990 Research Foundation - State Unversity of New York

March 1. 1990

$-21-$

Guide to the Uniform Data Set 
Functional Independence Measure - FIM (continued)

E: DRESSING - LOWER BODY Includes dressing from the waist down as well as donning or removing prosthesis or orthosis when applicable.

\section{NO HELPER}

7. Complete Independence--Dresses and undresses including obtaining clothes from their customary places such as drawers and closets: manages underpants, slacks, skirt, belt, stockings, and shoes; manages zippers. buttons, and snaps: dons and removes prosthesis or orthosis when applicable.

6. Modifled Independence--Requires special adaptive closure such as velcro, or assistive device (including a prosthesis or orthosis), or takes more than a reasonable time.

\section{HELPER}

5. Supervision or Setup--Requires supervision (e.g., standing by, cuing. or coaxing) or setup (application of orthosis, setting out clothes or dressing equipment).

4. Minlmal Contact Assistance--Subject performs $75 \%$ or more of dressing tasks.

3. Moderate Assistance--Performs $50 \%$ to $74 \%$ of dressing tasks.

2. Maximal Assistance--Performs $25 \%$ to $49 \%$ of dressing tasks.

1. Total Assistance--Performs less than $25 \%$ of dressing tasks, or is not dressed.

Copyright 1990 Research Foundation - State Undversity of New York

Guide to the Uniform Data Set 
Functional Independence Measure - FIM (continued)

F: TOILETING Includes maintaining perineal hygiene and adjusting clothing before and after tollet or bed pan use. Performs safely.

\section{NO HELPER}

7. Complete Independence--Cleanses self after voiding and bowel movement: puts on sanitary napkins/inserts tampons; adjusts clothing before and after using toilet.

6. Modified Independence--Requires specialized equipment (including orthosis or prosthesis) or takes more than reasonable time or there are safety considerations.

\section{HELPER}

5. Supervision or Setup--Requires supervision (e.g.. standing by. cuing. or coaxing) or setup (application of adaptive devices or opening packages)

4. Minimal Contact Assistance--Subject performs $75 \%$ or more of toileting tasks.

3. Moderate Assistance--Performs $50 \%$ to $74 \%$ of toileling tasks.

2. Madmal Assistance--Performs $25 \%$ to $49 \%$ of tolleting tasks.

1. Total Assistance--Performs less than $25 \%$ of toileting tasks.

Comment. If subject requires assistance with sanitary napkins (usually 3-5 days per month) level of asslatance is 5, supervision or setup. 
Functional Independence Measure - FIM (continued)

G: BLADDER MANAGEMENT Includes complete intentional control of urinary bladder and use of equipment or agents necessary for bladder control.

\section{NO HELPER}

7. Complete Independence--Controls bladder completely and intentionally and is never incontinent.

6. Modifled Independence--Requires a urinal, bedpan, commode. catheter. absorbent pad, diaper, urinary collecting device, or urinary diversion or uses medication for control: if catheter is used. the individual instills or irrigates catheter without assistance: cleans, sterilizes, and sets up the equipment for irrigation without assistance. If the individual uses a device, he/she assembles and applies condom drainage or an lleal appliance without assistance of another person: empties. puts on, removes, and cleans leg bag or emptles and cleans ileal appliance bag. No accidents.

\section{HELPER}

5. Supervision or Setup--Requires supervision (e.g., standing by, cuing, or coaxing) or setup (placing or emptying) of equipment to maintain a satisfactory voiding pattern or to maintain an extemal device: or because of the lapse of time to get to bedpan or the tollet the individual may have occasional bladder accidents, or bed pan or urinal spllls, but less often than monthly.

4. Minimal Contact Assistance--Requires minimal contact assistance to maintain an external device; the individual performs $75 \%$ or more of bladder management tasks: or may have occasional bladder accidents, but less often than weekly.

3. Moderate Assistance--Requires moderate assistance to maintain an external device: the individual performs $50 \%$ to $74 \%$ of bladder management tasks; or may have occasional bladder accidents, but less often than dailv.

2. Maximal Assistance--Despite assistance the individual is wet on a frequent or almost daily basis. necessitating wearing diapers or other absorbent pads. whether or not a catheter or ostomy device is in place. The individual performs $25 \%$ to $49 \%$ of bladder management tasks.

1. Total Assistance--Despite assistance the individual is wet on a frequent or almost dally basis. necessitating wearing diapers or other absorbent pads. whether or not a catheter or ostomy device is in place. The individual performs less than $25 \%$ of bladder management tasks.

Comment: The functlonal goal of bladder management is to open the bladder sphincter only when that is needed and to keep it closed the rest of the time. This may require devices. drugs or assistance in some individuals. This ltem. therefore. deals with two varlables: 1) level of success in bladder management and. 2) level of assistance required. Usually the two follow each other. e.g., when there are more accidents usually more assistance is required. However, should the two levels not be exactly the same. always record the lower level.

Copyright 1990 Research Foundation - State Unlversity of New York

Guide to the Uniform Data Set -24-

March 1. 1990 
Functional Independence Measure - FIM (continued)

H: BOWEL MANAGEMENT Includes complete Intentional control of bowel movement and use of equipment or agents necessary for bowel control.

\section{NO HELPER}

7. Complete Independence--Controls bowels completely and intentionally and is never incontinent.

6. Modified Independence--Requires bed pan or commode. digital stimulation or stool softeners, suppositories, laxatives, or enemas on a regular basis. or uses other medications for control. If the Individual has a colostomy, he/she malntains it. No accidents.

\section{HELLPE}

5. Supervision or Setup--Requires supervision (e.g., standing by. cuing, or coaxing). or setup of equipment necessary for the individual to maintain a satisfactory excretory pattern or to maintain an ostomy device: or the individual may have occasional bowel accidents, but less often than monthly.

4. Minimal Contact Assistance--Requires minimal contact assistance to maintain a satisfactory excretory pattern by using suppositories or enemas or an external device: the individual performs $75 \%$ or more of bowel management tasks; or the individual may have occasional bowel accidents, but less often than weekly.

3. Moderate Assistance--Requires moderate assistance to maintain a satisfactory excretory pattern by using suppositories or enemas or an external device; the individual performs $50 \%$ to $74 \%$ of bowel management tasks: or the individual may have occasional bowel accidents, but less often than dally.

2. Madmal Assistance--Despite assistance the individual is soiled on a frequent or almost dally basis, necessitating wearing diapers or other absorbent pads. whether or not an ostomy device is in place. The individual performs $25 \%$ to $49 \%$ of bowel management tasks.

1. Total Assigtance--Despite assistance the individual is soiled on a frequent or almost dally basis. necessitating wearing diapers or other absorbent pads. whether or not an ostomy device is in place. The individual performs less than $25 \%$ of bowel management tasks.

Comment: The funcuonal goal of bowel management is to open the anal sphuncter only when that is needed and to keep it closed the rest of the Ume. This may require devices. drugs or assistance in some indivduals. This item. therefore, deals with two vartables: 1) level of success in bowel managernent and. 2) level of assistance requited. Usually the two follow each other. E.g.. when there are more aceldents usually more assistance is required. However, should the two levels not be exactly the same, always recond the lower level.

Copyright 1990 Research Foundation - State University of New York

March 1, 1990

-25 -

Guide to the Uniform Data Set 
Functlonal Independence Measure - FIM (continued)

I: TRANSFERS: BED, CHAIR, WHEELCHAIR Includes all aspects of transferring to and from bed. chair. and wheeichair. and coming to a standing position. If walking is the typical mode of locomotion.

\section{NO HELPER}

7. Complete Independence

--- If walking. approaches. sits down and gets up to a standing position from a regular chair; transfers from bed to chair. Performs safely.

--. If in a wheelchair. approaches a bed or chalr. locks brakes, ufts foot rests. removes arm rest if necessary. and performs either a standing plvot or sliding transfer and returns. Performs safely.

6. Modified Independence--Requires adaptive or assistive device (including a prosthesis or orthosis) such as a sliding board. a lift. grab bars, or special seat or chalr or brace or crutches; takes more than reasonable time or there are safety considerations.

HELPER

5. Supervision or Setup--Requires supervision (e.g.. standing by. cuing, or coaxing) or setup (positioning sliding board, moving foot rests, etc.)

4. Minimal Contact Assistance--Subject performs $75 \%$ or more of transferring tasks.

3. Moderate Assistance--Performs $50 \%$ to $74 \%$ of transferring tasks.

2. Maximal Assistance--Performs $25 \%$ to $49 \%$ of transferring tasks.

1. Total Assistance--Performs less than $25 \%$ of transferring tasks.

Comment; When assessing bed to chalr transier. the subject begins and ends in the suplne position.

Copyright 1990 Research Foundation - State UnIversity of New York

Guide to the Uniform Data Set -26- March 1. 1990 
Functional Independence Measure - FIM (continued)

\section{J: TRANSFERS: TOILET Includes getting on and of a tollet.}

\section{NO FELPER}

7. Complete Independence

-- If walking, approaches, sits down on and gets up from a standard tollet. Performs safely.

-- If in a wheelchair, approaches tollet, locks brakes. lifts foot rests. removes arm rests if necessary and does either a standing pivot or sliding transfer and returns. Performs safely.

6. Modified Independence--Requires adaptive or assistive device (including a prosthesis or orthosis) such as a sliding board, a lift, grab bars. or special seat: takes more than reasonable time or there are safety considerations.

\section{HELPER}

5. Supervision or Setup--Requires supervision (e.g.. standing by. cuing. or coaxing) or setup (positioning sliding board, moving foot rests, etc.)

4. Minimal Contact Assistance--Subject performs $75 \%$ or more of transferring tasks.

3. Moderate Assistance--Performs $50 \%$ to $74 \%$ of transferring tasks.

2. Mardmal Assistance--Performs $25 \%$ to $49 \%$ of transferring tasks.

1. Total Assistance--Pefforms less than $25 \%$ of transferning tasks. 
Functional Independence Measure - FIM (continued)

K: TRANSFERS: TUB OR SHOWER Includes getting Into and out of a tub or shower stall.

\section{NO HELPER}

\section{Complete Independence}

-- If walking. approaches. enters and leaves a tub or shower stall. Performs safely.

-- If in a wheelchair, approaches tub or shower, locks brakes, lifts foot rests, removes arm rests if necessary, and does either a standing pivot or sliding transfer and returns. Performs safely.

6. Modified Independence--Requires adaptive or assistive device (including a prosthesis or orthosis) such as a sliding board. a lift. grab bars, or special seat: takes more than reasonable time or there are safety considerations.

\section{FIELPER}

5. Supervision or Setup--Requires supervision (e.g.. standing by, cuing. or coaxing) or setup (positioning sliding board, moving foot rests, etc.)

4. Minimal Contact Assistance--Subject performs $75 \%$ or more of transferring tasks.

3. Moderate Asgistance--Performs $50 \%$ to $74 \%$ of transferring tasks.

2. Mardmal Assistance--Performs $25 \%$ to $49 \%$ of transferring tasks.

1. Total Assistance--Performs less than $25 \%$ of transferring tasks.

Copyright 1990 Research Foundation - State University of New York 
Functional Independence Measure - FIM (continued)

\section{L: LOCOMOTION}

Includes walking. once in a standing position. or using a wheelchalr. once in a seated position. on a level surface. Check most frequent mode of locomotion. If both are about equal. check both $\mathrm{W}$ and C. If initiating a rehabllitation program. check the mode for which training is intended.

$$
\mathrm{W}=\text { walking } \quad \mathrm{C}=\text { wheelchhair }
$$

NO HELPER

7. Complete Independence--Walks a minimum of 150 feet without assistive devices. Does not use a wheelchair. Performs safely.

6. Modified Independence--Walks a minimum of 150 feet but uses a brace (orthosis) or prosthesis on leg. special adaptive shoes, cane, crutches, or walkerette: takes more than reasonable time or there are safety considerations.

If not walking. operates manual or electric wheelchair Independently for a minimum of 150 feet: turns around: maneuvers the chalr to a table, bed, toilet: negotiates at least a 3 percent grade; maneuvers on rugs and over door sills.

5. Exception (Household Ambulation)-- Walks only short distances (a minimum of 50 feet) with or without a device. Could take more than reasonable time, or there are safety considerations, or operates a manual or electric wheelchair independently only short distances (a minimum of 50 feet)

\section{HELPER}

5. Supervision--If walking, requires standing by supervision, cuing, or coaxing to go a minimum of $\underline{150}$ feet.

If not walking, requires standing by supervision, culing. or coaxing to go a minimum of 150 feet in wheelchair.

4. Minimal Contact Assistance--Subject performs $75 \%$ or more of locomotion effort to go a minimum of $\underline{150}$ feet.

3. Moderate Assistance--Performs $50 \%$ to $74 \%$ of locomotion effort to go a minimum of $\underline{150}$ feet.

2. Madimal Assistance--Performs $25 \%$ to $49 \%$ of locomotion effort to go a minimum of 50 feet. Requires assistance of one person only.

1. Total Assistance--Performs less than $25 \%$ of effort, or requires assistance of two people. or does not walk or wheel a minimum of 50 feet.

Copyright 1990 Research Foundation - State University of New York
March 1. 1990
-29-
Guide to the Uniform Data Set 
Functional Independence Measure - FMM (continued)

M: STAIRS Goes up and down 12 to 14 stalrs (one flight) indoors.

\section{NO HELPER}

7. Complete Independence--Goes up and down at least one flight of stairs without any type of handrail or support. Performs safely.

6. Modified Independence--Goes up and down at least one fight of stairs requiring side support or handrail, cane, or portable supports: takes more than reasonable time or there are safety considerations.

5. Exception (Household Ambulation)-Goes up and down 4 to 6 stairs independently, with or without a device. Could take more than reasonable time or there are safety considerations.

HELPER

5. Supervislon--Requires standing by supervision, culng, or coaxdng to go up and down one flight.

4. Minimal Contact Assistance--Subject performs $75 \%$ or more of effort to go up and down one flight.

3. Moderate Assistance--Performs $50 \%$ to $\mathbf{7 4} \%$ of the effort to go up and down one flight.

2. Maximal Assistance--Performs $25 \%$ to $49 \%$ of stair climbing effort to go up and down 4 to 6 stairs. Requires the assistance of one person only.

1. Total Assistance--Performs less than $25 \%$ of the effort or requires the assistance of two people. or does not go up and down 4-6 stairs, or is carried.

Copyright 1990 Research Foundation - State University of New York

Gulde to the Uniform Data Set $\quad-30-\quad$ March 1. 1990 
Functional Independence Measure - FIM (continued)

N: COMPREHENSION Includes understanding of elther auditory or visual communication (e.g. writing. sign language. gestures). Check and evaluate the most usual mode of comprehension. If both are about equally used. check both $\mathrm{A}$ and $\mathrm{V}$.

$$
\mathrm{A}=\text { Auditory } \quad \mathrm{V}=\text { Visual }
$$

\section{NO HELPER}

7. Complete Independence--Understands directions and conversation that are complex or abstract: understands either spoken or written native language.

6. Modifled Independence--Understands directions and conversation that are complex or abstract in most situations or with mild difficulty. No prompting is needed. May require a hearing or visual ald. other assistive device, or extra time to understand the information.

\section{HELPER}

5. Standby Prompting--Understands directions and conversation about basic dally needs more than $90 \%$ of the time. Requires prompting (slowed speech rate. use of repetition. stressing particular words or phrases. pauses; visual or gestural cues) less than $10 \%$ of the time.

4. Minimal Prompting--Understands directions and conversation about basic dally needs $75 \%$ to $90 \%$ of the time.

3. Moderate Prompting--Understands directions and conversation about basic dally needs $50 \%$ to $74 \%$ of the time.

2. Maximal Prompting--Understands directions and conversation about basic dally needs $25 \%$ to $49 \%$ of the time. May understand only simple questions or statements. Requires prompting more than half the time.

1. Total Assistance--Understands directions and conversation about basic dally needs less than $25 \%$ of the time or does not understand simple questions or statements or may not respond appropriately or consistently despite prompting.

Comment: Comprehension of complex or abstract Information includes, but is not limited to understanding: group conversation. current events appearing in televislon programs or newspaper articles, or abstract information such as religion, humor. math. or Inances used in dally living. information about basic dally needs refers to conversation. directions, question or statements related to the subject's need for nutrition, flulds, elimination. hyglene, sleep (physlological needs). 
Functional Independence Measure - FM (contlnued)

O: EXPRESSION Includes clear vocal or non-vocal expression of language. This item includes both intelligible speech or clear expression of language using writing or a communication device. Check and evaluate the most usual mode of expression. If both are about equally used, check both $\mathrm{V}$ and $\mathrm{N}$.

$$
\mathrm{V}=\text { Vocal } \quad \mathrm{N}=\text { Nonvocal }
$$

\section{NO HELPER}

7. Complete Independence--Expresses complex or abstract ideas clearly and Quently.

6. Modified Independence--Expresses complex or abstract ideas in most situations, or with mild difficulty. No prompting is needed. May require an augmentative communication device or system.

\section{HELPER}

5. Standby Prompting--Expresses basic dally needs and ideas more than $90 \%$ of the time. Requires prompting (e.g. frequent repetition) less than $10 \%$ of the time to be understood.

4. Minimal Prompting--Expresses basic dally needs and ideas $75 \%$ to $90 \%$ of the time.

3. Moderate Prompting--Expresses basic daily needs and ideas $50 \%$ to $74 \%$ of the time.

2. Marimal Prompting--Expresses basic dally needs and ideas $25 \%$ to $49 \%$ of the time. May use only single words or gestures. Needs prompting more than half the time.

1. Total Assistance--Expresses basic daily needs and ideas less than $25 \%$ of the time or does not express basic needs appropriately or consistently despite prompting.

Comment: Examples of complex or abstract ideas include. but are not limited to, discussing current events. religion. or relationships with others. Expresston of baslc needs and ideas refers to the subjecl's ability to communicate about necessary dally activilies such as nutrition. fluids. elimination, hyglene and sleep (physlological needs).

Copyright 1990 Research Foundation - State University of New York

Guide to the Uniform Data Set -32- March 1. 1990 
Functional Independence Measure - FIM (continued)

R: MEMORY Includes skills related to recognizing and remembering while performing daily activities in an institutional or community setting. It Includes ability to store and retrieve information, particularly verbal and visual. A deficit in memory Imipalrs learning as well as performance of tasks.

\section{NO HELPER}

7. Complete Independence--Recognizes people frequently encountered and remembers daily routines: executes requests of others without need for repetition.

6. Modifled Independence--Recognizes people frequently encountered. remembers daily routines and requests of others with mild difficulty. May use self-Initiated or environmental cues, prompts or alds.

\section{HELPER}

5. Supervision--Requires prompting (e.g., cuing. repetition, reminders) only under stressful or unfamiliar conditions, but no more than $10 \%$ of the time.

4. Minimal Prompting--Subject recognizes and remembers $75 \%$ to $90 \%$ of the time.

3. Moderate Prompting--Recognizes and remembers $50 \%$ to $74 \%$ of the time.

2. Madmal Prompting-Recognizes and remembers $25 \%$ to $49 \%$ of the time. Needs prompting more than half the time.

1. Total Assistance--Recognizes and remembers less than $25 \%$ of the tume or does not effectively recognize and remember. 
Functional Independence Measure - FRM (continued)

Q: PROBLEM SOLVING Includes skills related to solving problems of dally living. This means making reasonable. safe, and timely decisions regarding financial. social and personal affairs and initiating. sequencing and self-correcting tasks and activities to solve the problems.

\section{NO FELPER}

7. Complete Independence--Consistently recognizes a problem. makes appropriate decisions. Initiates and carries out a sequence of steps to solve complex problems until the task is completed, and self-corrects if errors are made.

6. Modified Independence--Recognizes a problem, makes appropriate decisions. initiates and carties out a sequence of steps to solve complex problems in most situations. or with mild difficulty, or requires more than a reasonable time to make decisions about or solve complex problems.

\section{HELPER}

5. Supervision--Requires supervision (e.g., cuing, or coaxing) to solve routine problems only under stressful or unfamiliar conditions, no more than $10 \%$ of the time.

4. Manimal Direction--Subject solves routine problems $75 \%$ to $90 \%$ of the time.

3. Moderate Direction--Solves routine problems $50 \%$ to $74 \%$ of the time.

2. Maximal Direction--Solves routine problems $25 \%$ to $49 \%$ of the time. Needs direction more than half the time to initiate, plan or complete simple daily activities. May need restraint for safety.

1. Total Assistance--Solves routine problems less than $25 \%$ of the time. Needs direction nearly all the time, or does not effectively solve problems. May require constant 1:1 direction to complete simple dally activities. May need a restraint for safety.

Damples of problems: Complex problem solving includes activitles such as: managing a checking account. participating in discharge plans, self-administration of medications, confronting Interpersonal problems, and making employment declstons. Rouline problems include successfully complelling dally tasks or dealing with unplanned events or hazards that occur during dally activitues.

Copyright 1990 Research Foundation - State University of New York

Guide to the Uniform Data Set

March 1. 1990 
Functional Independence Measure - FDM (continued)

P: SOCLAL INTERACTION Includes skllls related to getting along and participating with others in therapeutic and social situations. It represents how one deals with one's own needs together with the needs of others.

\section{NO HELPER}

7. Complete Independence--Interacts appropriately with staff, other patients. and family members (e.g.. controls temper. accepts criticism. is aware that words and actions have an impact on others).

6. Modified Independence--Interacts appropriately with staff, other patients. and family members in most situations or with mild difficulty. No supervision is required. May require more than a reasonable time to adjust in soclal situations or may require medication for control.

\section{HELPER}

5. Supervision--Requires supervision (e.g., montoring; verbal control: cuing, or coaxing) only under stressful or unfamillar conditions, but no more than $10 \%$ of the time. May require encouragement to initiate participation.

4. Minimal Direction--Subject interacts appropriately $75 \%$ to $90 \%$ of the time.

3. Moderate Direction--Interacts appropriately $50 \%$ to $74 \%$ of the time.

2. Marimal Direction--Interacts appropriately $25 \%$ to $49 \%$ of the time. May need restraint.

1. Total Assistance--Interacts appropriately less than $25 \%$ of the time, or not at all. May need restraint.

Examples of socially tnapproprtate behaviors: temper tantrums; loud. foul. or abusive language: excessive laughing. crying: physical attack; or very withdrawn or non interactive. 
81

APPENDIX E

Human subjects Approval 
Otfice of the Acadamic Vice Proeldent - Associelo Acodomic Vice Prosident - Gredualo Sludies and Rosearch

One Whanington Square - Sen Jose. Californta 95192-0025 - 408/924-2480

TO:

Jacalyn wiedenhoeft

$2729 \mathrm{~W}$. Sierra

Fresno, CA 93711

FROM :

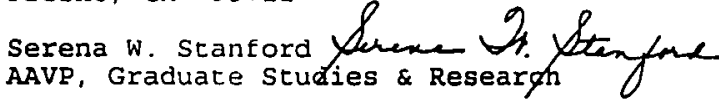

DATE :

October 10, 1994

The Human Subjects-Institutional Review Board has approved your request to use humans subjects in the study entitled:

"The Relationship Between the Glasgow coma Scale and the

Functional Independence Measure of Adult Individuals with Brain Injury

This approval is contingent upon the subjects participating in your research project being approriately protected from risk. This includes the protection of the anonymity of the subjects' identity when they participate in your research project, and with regard to any and all data that may be collected from the subjects. The Board's approval includes continued monitoring of your research by the Board to assure that the subjects are being adequately and properly protected from such risks. If at any time a subject becomes injured or complains of injury, you must notify Dr. Serena Stanford immediately. Injury includes but is not limited to bodil. harm, psychological trauma and release of potentially damaging personal information.

Please also be advised that each subject needs to be fully informed and aware that their pariticpation in your research project is voluntary, and that he or she may withdraw from the project at an: time. Further, a subject's participation, refusal to participate, or withdrawal, will not affect any services the subject is receiving or will receive at the institution in which the research is being conducted.

If you have any questions, please contact me at (408) 924-2480. 
APPENDIX $\mathbf{F}$

Facility Approval 


\title{
(e) Leon S. Peters Rehabilitation Center Community Hospitals of Central California
}

Fresno 8 "A" Strouts, Frusno CA 93721/P.O. BOX 1232, Frosno. CA 93715, (209) 442.3957, (600) 628-909!?

\section{HEMORAYWUS OF OKDERSTANDING}

\begin{abstract}
Jackie Wiedenhoeft, OTR has been granted permission to use information regarding patients treated at the Leon S. Peters Rehabilitation Center in preparation of her Masters Thesis for a masters in occupational therapy at San Jose State University. This will include demographic information obtained from the medical record, and Punctional Independence Measure (FIM) outcome scores from the occupational therapy vorking files.
\end{abstract}

Any information collected vill be used in an aggregate fashion (versus single study data) and vill not divulge patient identiflcation or breach patient confidentiality in any way.

Brenda P. Collins, OTR, as Manager of Occupartonal Therapy, will have the right to review any document that will be made public prior to its publication to assure patient confidentiality.

Jackie Miedenhoeft, OTR, agrees to treat all information in a confidential manner.

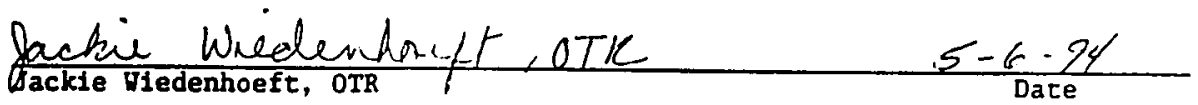

$\frac{\text { Biende P. Creurs ote }}{\text { Brenda P. Collins, OTR }} \frac{5-4-94}{\text { Date }}$

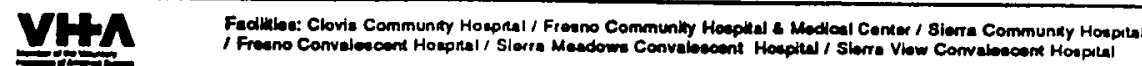

